Review Article

\title{
A Content Analysis and Meta-Analysis on the Effects of Classcraft on Gamification Learning Experiences in terms of Learning Achievement and Motivation
}

\author{
Qi Zhang ${ }^{1},{ }^{1}$ Liheng $Y u^{2}$ and Zhonggen Yu ${ }^{1}{ }^{1}$ \\ ${ }^{1}$ Faculty of Foreign Studies, Beijing Language and Culture University, 15 Xueyuan Road, Haidian District, Beijing 100083, China \\ ${ }^{2}$ School of Electronic Engineering, Jiangsu Ocean University, 59 Cangwu Road, Haizhou District, Lianyungang 222005, \\ Jiangsu, China
}

Correspondence should be addressed to Zhonggen Yu; 401373742@qq.com

Received 4 June 2021; Revised 18 October 2021; Accepted 20 October 2021; Published 20 November 2021

Academic Editor: Ehsan Namaziandost

Copyright (c) 2021 Qi Zhang et al. This is an open access article distributed under the Creative Commons Attribution License, which permits unrestricted use, distribution, and reproduction in any medium, provided the original work is properly cited.

\begin{abstract}
Classcraft has become an attractive gamification choice that turns classes into motivating and joyful role-playing experiences. Based on the content analysis and meta-analysis, this study aims to investigate the efficiency of Classcraft in terms of optimal gamification learning experiences associated with learning achievement and motivation. After the identification, screening, eligibility, and inclusion processes, we have found that learning achievement and motivation are significant factors conducive to optimal gamification learning. The meta-analysis based on STATA 15 has demonstrated that gamification platforms including Classcraft can similarly enhance learning achievement $(d=0.621, z=5.846,95 \%$ CI $[0.413,0.829])$ and motivation $(d=0.608$, $z=6.167,95 \%$ CI $[0.415,0801])$, suggesting that gamification platforms including Classcraft can create optimal learning experiences. Another content analysis has revealed that Classcraft involving gamified reward mechanics, interactive settings, and collaborative tasks can fulfil the conditions of optimal gamification learning experiences. The main conclusion is that Classcraft can efficiently create optimal gamification learning processes that can positively influence learning achievement and motivation. We have also discussed the potential reasons for the positive effects of gamification on learning achievement and motivation. Game implementation can reflect learners' preference for well-being based on continuity, interaction, and openness.
\end{abstract}

\section{Introduction}

Even given the circumstance of COVID-19, educators still attempt to seek efficient pedagogical practices that stimulate interest in learning [1]. Accordingly, instructors should adapt to online learning and create attractive and motivating learning environments that positively influence learners' awareness of making progress $[2,3]$.

Gamification, the phenomenon of using gamified elements in non-game contexts, belongs to the motivating pedagogical approaches [3-8]. Since this approach is applicable to face-to-face traditional instructional techniques and online learning contexts [9], instructors can make full use of gamification to improve learners' academic performance, motivation, and immersion [3].
Classcraft is an online and free gamification platform that enables instructors to turn classes into role-playing games [10] and learners to obtain knowledge in immersive gamified settings $[11,12]$ (see Figure 1). Initially launched in 2014, Classcraft aims to create an award-winning and userfriendly atmosphere for gamification learning [13]. Nowadays, Classcraft has appeared in more than 50,000 classrooms in 75 countries in 11 languages as a supplementary pedagogical practice tool [13].

Researchers have conducted studies on Classcraft. Haris and Sugito [14] have investigated the factors associated with learners' acceptance of Classcraft. The results have demonstrated that e-learning motivation and behaviour intention were beneficial for learners' acceptance of Classcraft [14]. 


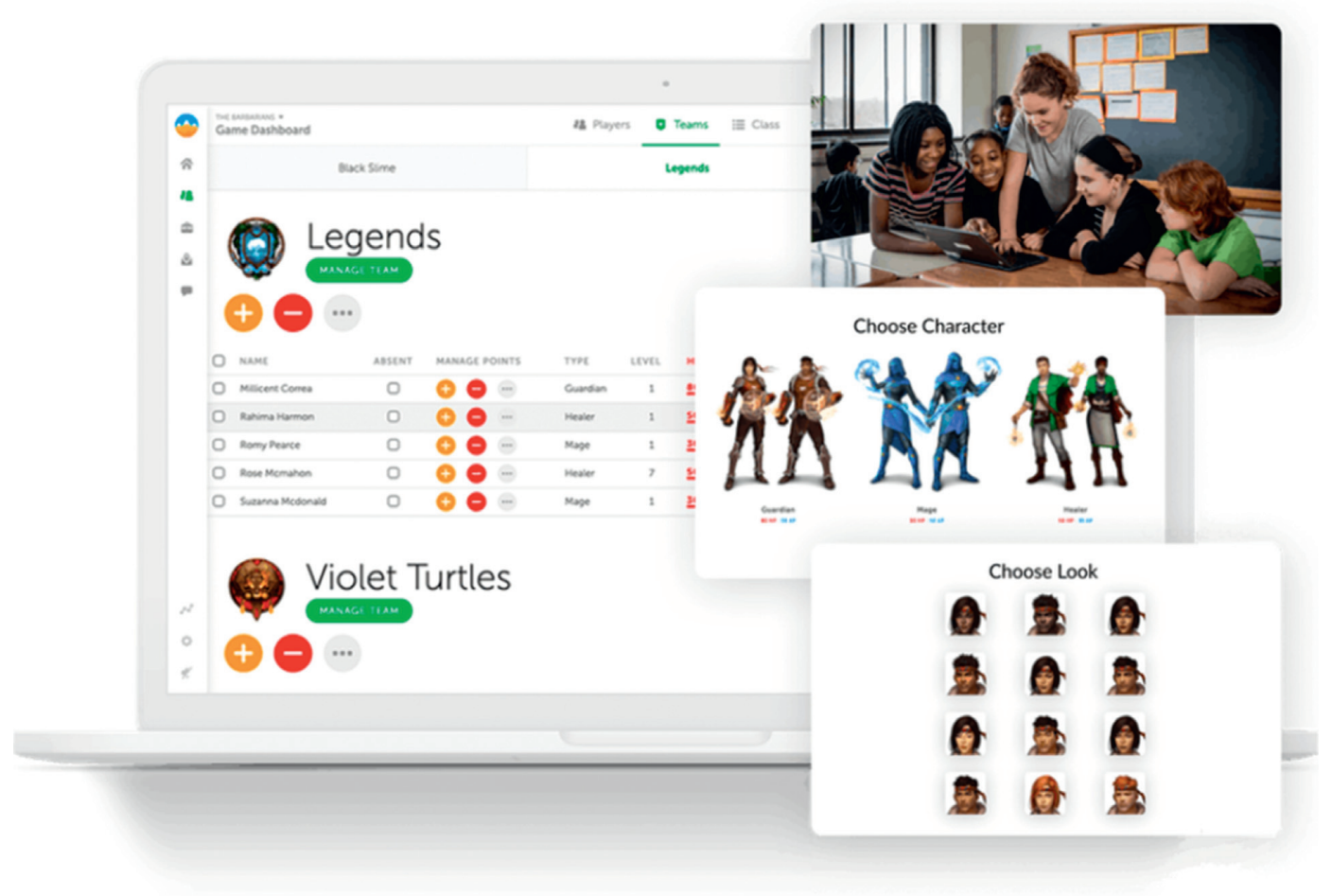

Figure 1: A screenshot of gamification designs in Classcraft (https://www.classcraft.com).

Besides, Freire and Carvalho [15] have investigated the effects of Classcraft on math learning. The results have revealed that Classcraft can positively impact learners' engagement in learning and academic performance in math [15].

Moreover, River-Trigueros and Sánchez-Pérez [11] have analyzed the impacts of Classcraft on learners' motivation and English proficiency. They have found that Classcraft can positively influence learners' extrinsic motivation, participation, and English learning outcomes [11].

Considering the research goals, this study first aims to confirm the efficiency of Classcraft through the content analysis and meta-analysis. Past studies mainly focus on learning achievement and motivation. Learning achievement is the common criterion evaluating how learners have made progress in academic performance [3]. The motivational power of games also reflects the significant role of motivation in measuring the efficiency of game implementation [16].

Apart from learning achievement and motivation, learners' experiences based on specific mental states matter in game implementation because optimal mental states can contribute to conscious and rational reasoning or decision making in pedagogical practices [6]. Thus, we can investigate the efficiency of Classcraft in terms of optimal gamification learning experiences, learning achievement, and motivation.

Additionally, this study aims to differentiate gamification from serious game based on distinctive features. As an increasing number of game-related concepts have emerged, we should not confuse gamification and gamification. Judging whether Classcraft belongs to a gamification platform or a serious game can present which factors this platform emphasizes in pedagogical practices for maximized efficiency.

Furthermore, this study aims to demonstrate the value of pedagogical practices involving game implementation. The studies of Boller [17] and Wang et al. [18] have revealed that some people still doubt the efficiency of game implementation in pedagogical education because game elements lack seriousness. For that reason, we should investigate the efficiency of Classcraft in terms of gamification learning experiences.

\section{Literature Review}

This section focuses on the distinctions between serious games and gamification. Based on past studies, we can know to which game-related types Classcraft belongs. We can conduct corresponding processes to investigate the effects of this platform.

2.1. The Distinctions between Gamification and Serious Games. Gamification first appeared in late 2010 based on industry players' efforts [19]. Along with the emergence of this term, numerous game and user experience designers have proposed other related terms. Among these terms, playing and gaming have gained researchers' much attention [20].

The distinction between playing and gaming is a significant criterion to distinguish game-related types [21]. Playing refers to free-form, non-rule-based, and expressive 
actions, while gaming stands for rule-based and goal-oriented playful activities [21]. Since games should involve rulebased, voluntary, and enjoyable activities that can produce goods of external value [21], gaming necessitates explicit rule systems and outcomes [22].

The distinctions between playing and gaming have paved the path for the development of game-related concepts and theories. McGonigal [23] has introduced two concepts: playfulness and gamefulness, respectively consistent with playing and gaming. Deterding et al. [19] have proposed the dimension of playing versus gaming.

Deterding et al. [19] have put forward two dimensions to differentiate gamification, serious games, toys, and playful designs (see Figure 2). The dimension gaming versus playing reflects whether the product involves rule-bounded and outcome-related elements or just consists of the playing aspect $[19,20]$. The dimension whole versus parts demonstrates the extent to which a product is using gaming elements $[19,20]$.

Thus, according to these two dimensions, gamification partly requires gaming elements with other aspects of the product untouched, whereas serious games require complete game designs with an education or learning background $[19,20]$. These are the core distinctions between gamification and serious games.

In summary, serious games usually require game designs through the activities, while gamification can exist without games by employing elements in everyday contexts to motivate and engage players [24]. Serious games involve a set of rules and actions in a cohesive manner, motivating players to compete with others. Participants can play serious games in teams to facilitate collective awareness and community spirit. At the end of pedagogical practices, serious games usually involve winners or losers after competitions [24].

By contrast, gamification includes elements from game designs and does not necessarily require the form of games. Gamification enables players to achieve immersion in the gamified designs and improve their performance by selfchallenges [24]. Gamification also requires rule-based goaloriented designs that encourage players to progress by completing tasks or surpassing others $[19,20]$. At the end of activities, gamification stresses slightly competitive game elements that encourage players to make progress relatively irrespective of others' performance [24].

Admittedly, although the researchers have discussed the distinction between playing and gaming, experimental procedures conducted by Salen and Zimmermann [22] and Groh [5] have demonstrated that people can integrate these concepts and that the distinction might remain theoretical to some extent.

Oliveira and Petersen [24] have argued that serious games emphasize the supportive role of Information and Communications Technology (ICT) in playful engagement conducive to raised awareness, understanding, and mastery of specific concepts or skills. In contrast, gamification highlights facilitation or constraint of specific behaviours based on immersive experiences on the ICT platform [24].

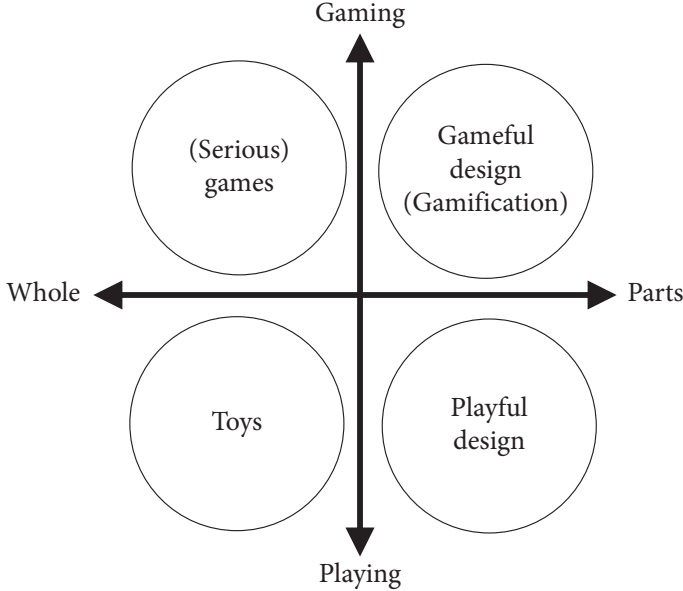

Figure 2: Whole versus parts and gaming versus playing as two dimensions distinguish game-related concepts [19].

Although serious game and gamification can engage players, the former usually provides implicit engagement in a relatively holistic manner. The latter approach usually offers engagement in specific behaviours in a relatively incorporated manner [24], consistent with the findings of Deterding et al. [19].

2.2. Classcraft as a Gamification Platform. Classcraft is a cloud-based platform aiming to transform the classroom into a role-playing game [10]. We should identify Classcraft as a gamification platform or a serious game based on its features.

Classcraft involves flexible designs. Instructors do not need to restrict Classcraft in one specific subject or specific periods [10]. Learners can participate in the curricular gamified tasks or enjoy extracurricular gamified activities [25].

Besides, instructors can design rules, rewards, or punishment in real life according to the game mechanics $[10,12,26]$. Instructors can customize the direct impact of the designs based on mechanics on learners' real lives for better adjustment to the classroom setting [10]. Thus, Classcraft highlights flexible application without temporal or spatial restrictions, consistent with the feature of part in gamification [19].

Classcraft focuses on players' behaviours. This platform enables instructors to foster learners' desired behaviours related to classroom management [10, 14, 27, 28]. For instance, learners can ensure attendance, participation, collaboration with other learners, and interaction with class instructors [29-31].

The reward and penalty systems in Classcraft encourage learners to recognize appropriate and inappropriate behaviours $[10,14,29,32]$. As the game activities process, positive behaviours enable learners to make progress, gain levels, acquire powers to advance their avatars, and support their team in the gamified world $[10,33]$.

Thus, learners can gain feedback from Classcraft mainly based on their behaviours. Indeed, players' behaviours can 
contribute to their immersive playful experiences in Classcraft [34] rather than the results of winning. Without the significantly explicit purpose of winning, Classcraft is consistent with the gamification that requires immersion [24].

Classcraft has comprehensive game features. Classcraft reflects multiplayer online role-playing games (MMORPGs) where an avatar represents and distinguishes each player (Grande-de-Peado and Baelo) [10, 32, 35]. This platform divides learners into teams involving four to six members and allows them to choose avatars: Mages, Warriors, or Healers [11, 12].

Besides, comprehensive competition is the second feature [10]. Classcraft leverages competitions between players and the game itself based on their behaviours [10]. This platform also leverages competitions among players based on the points that allow them to advance in relation to their mates [10].

Moreover, Classcraft emphasizes randomness [10]. The beginning of gamified experiences in Classcraft includes a series of random events that might influence the entire class and increase challenges [10].

Thus, the comprehensive game features are congruent with the feature of playing in gamification [19]. The game mechanics ensure the rule-based designs conducive to learners' active behaviours in achieving goals [19, 20]. Learners can enjoy learning experiences without the pressure of heated competition, reflecting the balance between self-challenges and competition against others [10, 24].

Overall, Classcraft presents flexible designs that emphasize players' behaviours conducive to engagement, rulebased and entertaining RPG experiences, and a balance between self-improvement and competition. These features demonstrate that Classcraft is a gamification platform rather than a serious game that mainly stresses educational purposes and winning goals.

Having summarized that Classcraft belongs to gamification designs, we can investigate the effects of Classcraft on pedagogical practices in terms of gamification. Since Classcraft creates immersive gamification learning experiences for learners [10], we can investigate the efficiency of Classcraft in terms of the experiences.

Considering gamification, learning achievement and motivation play indispensable roles because these two concepts are the two significant criteria reflecting the efficiency of the game-related pedagogical approaches $[3,16]$. Thus, we can investigate whether learning achievement and motivation belong to the factors conducive to optimal gamification learning experiences as the following research question presents.

RQ1: can learning achievement and motivation contribute to optimal gamification learning experiences?

If learning achievement and motivation can contribute to optimal gamification learning experiences, we could investigate the effects of gamification designs including Classcraft on these factors. The following research questions could meet the demand of analyzing the efficiency of gamification platforms in terms of optimal gamification learning experiences.
RQ2: can gamification platforms including Classcraft positively influence learning achievement and motivation for optimal gamification learning experiences?

Based on the investigation on the effects of gamification designs, we could specifically focus on Classcraft and analyze whether this platform can create optimal gamification learning experiences by enhancing learning achievement and motivation. The following research question reflects the efficiency of Classcraft.

RQ3: can Classcraft fulfil the conditions of optimal gamification learning experiences to positively influence learning achievement and motivation?

\section{Methodology}

This section concentrates on the research methods that we have applied to conduct the content analysis and metaanalysis. The methods include identification, screening, eligibility, and inclusion. We have also investigated the metaanalysis parameters according to the experimental scales in the studies.

3.1. Literature Search Based on Identification. We have adapted the research criteria in the study of Sailer and Homner [16] for our literature search to guarantee the research sensitivity and scope. We have not restricted the publication year. The search scope covers Web of Science, Eric, IEEE Xplore, PubMed, and SpringerLink.

We have used the following terms: Classcraft, or gamifi $*$, and experiment $*$. Having gained 1135 results from the initial research, we have refined the results separately by the keywords "learning achievement" and "motivation". After refining the initial results and removing the duplicate records, we have gained 275 potentially eligible records.

3.2. Screening and Eligibility for the Content Analysis. Considering the content analysis, the study of Dyba and Dingsøyr [36] has provided valid references for searching the studies that can present useful information about gamification learning and Classcraft. We have followed the following inclusion criteria for the content analysis:

(1) The article is published in an international peerreviewed journal, public online platform, or conference

(2) The article refers to Classcraft, gamification learning, or gamification-related concepts in the title, abstract, and text body

(3) The article accessible on the online databases should contain sufficient information about Classcraft, gamification learning, or conditions conducive to gamification learning

Admittedly, we have also extracted the studies based on the following exclusion criteria:

(1) The article is irrelevant to the keywords above

(2) The article is not accessible on any platform 
3.3. Screening and Eligibility for the Meta-Analysis. We have gained the possible eligible records and selected the eligible studies based on the following inclusion criteria:

(1) Regarding research topic, eligible studies should clearly describe the efficiency of gamification or serious games in terms of effects on learning achievement or motivation or present the comparisons of these game-related approaches

(2) Regarding research design, eligible studies should contain quantitative statistical methods examining the effects of game-related approaches on learning achievement or motivation

(3) Regarding the experiment conditions, eligible studies should involve comparison between experimental group and control group and compare at least one game-related condition with at least one condition based on another instructional approach

(4) Regarding the availability of statistical data, eligible studies should report sufficient statistical findings, including the numbers of participants, means, and standard deviations, allowing for applying metaanalytic techniques

During the selection process, we needed to concentrate on the abstract and full-text contents at the screening and eligibility stage, respectively. Based on the following exclusion criteria, we can select the studies consistent with the requirements of our study:

(1) The studies do not involve any experimental or statistical procedures but reviews

(2) The studies do not clearly describe the experiment topics or the target items assessed in the experimental procedures

(3) The studies do not present sufficient information allowing for meta-analytical techniques

3.4. Inclusion for Final Samples. We have extracted the eligible studies from the initial literature records. We have gained 18 studies about Classcraft that can be used for the content analysis on the efficiency of Classcraft (see Table 1) and 27 studies for the meta-analysis [15, 34, 37-61] (see Table 2).

The studies about Classcraft can demonstrate the features of Classcraft, the effects of Classcraft in specific experiments, possible factors influencing gamification learning, and implications of using game-related approaches in pedagogical practices (see Table 1). The studies for the meta-analysis involve experiments that examine the efficiency of gamification platform including Classcraft on learning achievement and on motivation (see Table 2).

3.5. Statistical Analysis in the Meta-Analysis. Notably, we have combined several sets of figures for the meta-analysis because several studies contain similar research dimensions. Thus, we have used the platform StatTools: Combine Means and SDs into One Group Program (https://www.obg.cuhk.edu.
hk/ResearchSupport/StatTools/CombineMeansSDs_Pgm.php) created by The Chinese University of Hong Kong to combine the data.

We have used STATA 15 to conduct the meta-analysis. Since heterogeneity among the experimental conditions and participants samples determines the models for the analysis [62], we should pay attention to the heterogeneity of the data in a broad range.

Since the studies have demonstrated different scales to report data, we have used Cohen's d, the statistic parameter of standardized mean difference (SMD), to investigate the difference between the means of the experimental and control groups in terms of the pooled standard deviation [62].

\section{Results}

This section presents the study results. Having identified, extracted, and reviewed past studies, we have first investigated the roles of learning achievement and motivation in optimal gamification learning.

\subsection{Can Learning Achievement and Motivation Contribute to} Optimal Gamification Learning Experiences? Based on the studies related to gamification learning experiences, we could investigate the roles of learning achievement and motivation in learners' mental states and growth processes.

\subsubsection{Flow in Learning Experiences and the Conditions} Conducive to Flow. Learners usually experience different mental states while participating in pedagogical activities. Flow refers to the optimal state, suggesting that learners tend to completely involve themselves in challenging but enjoyable activities [3].

Considering the conditions conducive to this optimal mental state, Csikszentmihalyi [63] has formulated a twodimensional model involving anxiety zone, boredom zone, and flow state to describe the possible mental states based on the relation between challenges and skills. Excessive challenges lead to the anxiety stage, indicating that tasks arouse learners' worry $[3,63]$. In contrast, insufficient difficulty leads to the boredom stage, suggesting that the tasks fail to stimulate learners'interest in making progress [3, 63].

Based on that model, Radoff [64] has proposed eight mental states influenced by the relation between challenge levels and skill levels: flow, arousal, control, relaxation, anxiety, worry, apathy, and boredom (see Table 3). The transition among arousal, flow, and control is positively associated with learning experiences [3, 6, 64]. The oscillation between arousal and control can balance challenges and skills $[3,6,64]$.

Therefore, optimal learning experiences are not static. Learners in the flow state should experience transitions between challenges and skills. Excessive perception of arousal or control cannot contribute to further progress. For that reason, a motivating learning experience can create a cycle of mental states (i.e., from arousal to flow to control and to arousal) [6]. 
TABLE 1: The studies on Classcraft and extracted for the content analysis.

\begin{tabular}{lr}
\hline Author(s) and year & Research methods \\
\hline Bonvin and Sanchez, 2017 & $\begin{array}{c}\text { Experiments based on playing analytics } \\
\text { detecting engaged-behaviors }\end{array}$
\end{tabular}

Bretherton, Sim, and Read, 2016

Ceballos and Parody, 2018

Climent and Martinez, 2018

Eugenio and Ocampo, 2019

Ferriz-Valero, Osterlie, Martinez, and Garcia-Jaen, 2020

Freire and Carvalho, 2019

Garcia-Garcia, Serrano, and Escrig, 2016

Grande-de-Peado, Baelo, Garcia-Martin, and AbellaGarcia, 2020
Experiential learning activities assessing learners' behaviours

Experiential learning lasting two semesters

Experiential learning activities

Researches based on the learning theory

Experiments involving the comparison between experiment and control groups

Experiments involving the comparison between experiment and control groups

Experimental proposal

Systematic literature review
Major findings

This study aims to characterize the social component of learners' engagement through playful experiences in

Classcraft. This work is grounded on the idea that players' engagement encompasses four components

(environmental, social, self-component, and action).

Based on playing analytics to monitor learners' behaviour, the results have demonstrated that Classcraft can enhance environmental, social, self-component, and action engagement and that social engagement varies across time, classroom, or gender.

This study examines the appropriateness of Classcraft for integration into primary classrooms within a UK context. Game design can positively influence classroom management in the primary school classroom.

Based on Classcraft, learners have obtained higher mean mark in the second semester than that in the first semester. Besides, the gamification activities can enhance critical thinking, communication, collaboration, and creativity. Overall, Classcraft can positively influence course participants' performance by fostering motivation. The implementation of Classcraft can improve grammatical and lexical contents like adjectives, gender flexion, use of personal data, or construction of simple sentences. The flexibility of gamification activities allows learners and instructors to work with intercultural, sociocultural, or affective components.

As a learner-centered gamification platform, Classcraft involves motivating game elements that enhance learners' behaviours, consistent with the behaviourism learning theory. Learners' self-assessment and instructor's assessment make Classcraft efficient in evaluating learning capacity.

The experiment results have demonstrated that Classcraft can contribute to an increase in academic performance and external regulation. The findings have suggested that gamified implementation is beneficial for academic performance at the university stage, even though intrinsic motivation does not significantly change.

The experiment results have revealed that Classcraft can improve learners' academic achievement by engaging them in playful learning processes. The results reflect the advantages of using technology and the gamification of the teaching strategies in pedagogical practices.

This study proposes an experimental proposal aiming to enhance learners' motivation from vocational programmes at upper education studies by means of game-based learning (GBL) methodologies. Classcraft is a learning management system (LMS) tool allowing learners to achieve motivation by receiving rewards or penalties according to their behaviours or obtained results.

Review results have revealed that educators tend to incorporate elements of RPGs in applications like learning management systems (e.g., Classcraft even though this trend do not seem to have had a very significant impact). Although there is an interest in roleplaying games in education, especially in Spain, but their potential is still to be developed. 
TABLE 1: Continued.

\begin{tabular}{lc}
\hline Author(s) and year & Research methods \\
\hline Haris and Sugito, 2015 & Researches involving observation, \\
questionnaires, and interviews
\end{tabular}

Haris and Sugito, 2015

Márquez and Torralbo, 2021

Papadakis and

Kalogiannakis, 2018

Poy and Garcia, 2019

Rivera-Trigueros and

Sánchez-Pérez, 2020a

Rivera-Trigueros and Sánchez-Pérez, 2020b

Sanchez, Young, and Jouneau-Sion, 2017

Sipone, Abella-García, Rojo, and dell'Olio, 2021

Torres, Durant, and Paredes, 2019
Experiments involving the comparison between experiment and control groups

Experiential learning activities

Review

Experiments involving the comparison between pre- and posttest results

Feedback from experiments and questionnaires

Comparison of learners' knowledge about sustainable mobility before and after the implementation of Classcraft based on questionnaire

Evaluation research
Major findings

This study is based on the modified model of the unified theory of acceptance and use of technology (UTAUT). The research results have revealed that Classcraft can positively influence e-learning motivation, facilitating conditions and behavioural intention.

This proposal focuses on the effects of Classcraft on English learning, with the aim of alleviating the disinterest and general apathy before the challenge of learning the grammar of the Anglo-Saxon language. The gamification

platform can promote teamwork and the use of information and communication technologies in situations that require the translation and interpretation of texts.

Gamification can create inspiring learning environments conducive to large increases in learners' interest in programming. Classcraft can provide fun learning experiences and promote teamwork. The experiment results have revealed that Classcraft can enhance learners' engagement.

Classcraft based on idealized images and fantastic environments is a powerful multiplier factor conducive to cognitive and attitudinal stimulation in learners.

Instructors can conduct visual learning activities by introducing role-playing characters based on the combination of gameful designs. Aesthetics and creativity of these elements can enhance learners' apprentice to boost interactive skills in the learning experience. The implementation of Classcraft can enhance Englishmedium instruction in higher education. Classcraft can positively influence learners' engagement, academic performance, motivation, and participation.

The research results have demonstrated that the gamification platform Classcraft can significantly improve learners' motivation. Classcraft can involve and engage learners in the English as a Foreign language (EFL) classroom.

The experiment results have revealed that Classcraft can enhance motivation about scholarly work and engagement in class work. Although behavioral problems

have not disappeared completely, computer access enables learners to enjoy interactions without disturbing the courses. Classcraft can increase learners' exposure to the classes metaphorized as battles combining collaboration and competition. As metaphorization changes classroom interactions, Classcraft can transform classroom situation, meanings of learners' behaviours, and learners' experiences, reflecting the core features of ludicization.

The experience has shown that by using the gamified Classcraft can enhance all aspects of sustainable mobility. Classcraft inspire learners to actively change and refine their class behaviours that can positively influence their comprehension of new concepts about the social and economic components of sustainable mobility. Classcraft involving game elements that complement the educational practice activities enables learners to interact through personalized avatars. The research results have revealed that Classcraft can improve learners' and instructors' motivation and commitment. 
TABLE 2: The studies examining the effects of gamification platforms including Classcraft and extracted for the meta-analysis

\begin{tabular}{|c|c|c|c|}
\hline No. & Author & Year & Research foci \\
\hline 1 & Alcalá \& Garijo & 2017 & Learning achievement \& Motivation \\
\hline 2 & Arnab et al. & 2013 & Learning achievement \\
\hline 3 & C.-H. Chen \& Yeh & 2019 & Learning achievement \& Motivation \\
\hline 4 & C.-Y. Hung et al. & 2018 & Motivation \\
\hline 5 & Cechella et al. & 2021 & Learning achievement \\
\hline 6 & Çetinkaya & 2019 & Learning achievement \\
\hline 7 & Cichy et al. & 2020 & Learning achievement \\
\hline 8 & Cun-Ming Hung et al. & 2014 & Learning achievement \& Motivation \\
\hline 9 & Duggal et al. & 2021 & Learning achievement \\
\hline 10 & Ferriz-Valero et al. & 2020 & Motivation \\
\hline 11 & Freire \& Carvalho & 2019 & Learning achievement \\
\hline 12 & Haruna et al. & 2018 & Motivation \\
\hline 13 & Hodges et al. & 2021 & Learning achievement \\
\hline 14 & H.-T. Hung & 2018 & Motivation \\
\hline 15 & Hwang et al. & 2013 & Learning achievement \& Motivation \\
\hline 16 & Hwang et al. & 2017 & Learning achievement \& Motivation \\
\hline 17 & Lee et al. & 2020 & Learning achievement \& Motivation \\
\hline 18 & Lin et al. & 2021 & Motivation \\
\hline 19 & Magen-Nagar et al. & 2019 & Motivation \\
\hline 20 & Ou et al. & 2021 & Learning achievement \\
\hline 21 & Özer et al. & 2018 & Motivation \\
\hline 22 & Pan et al. & 2019 & Learning achievement \& Motivation \\
\hline 23 & Papadakis \& Kalogiannakis & 2018 & Learning achievement \\
\hline 24 & Sánchez et al. & 2020 & Learning achievement \& Motivation \\
\hline 25 & Scales et al. & 2016 & Learning achievement \\
\hline 26 & $\mathrm{Su}$ & 2017 & Motivation \\
\hline 27 & Vázquez-Cano et al. & 2021 & Motivation \\
\hline
\end{tabular}

TABLe 3: The eight mental states influenced by the relation between challenge levels and skill levels [64].

\begin{tabular}{|c|c|}
\hline Mental states & Descriptions of the corresponding mental states \\
\hline Flow & $\begin{array}{l}\text { Flow is the optimal mental state because it balances the perceived challenges and the perceived skills. However, learners can } \\
\text { hardly keep the flow state all the time. Learners generally experience the transition between arousal, flow, control, and } \\
\text { relaxation while participating in gamified activities. }\end{array}$ \\
\hline Arousal & $\begin{array}{c}\text { Arousal indicates that the challenge level is somewhat higher than the learners' current skill level. Thus, this state motivates } \\
\text { learners to narrow the gap through practices. However, learners constantly influenced by this state tend to feel frustrated and } \\
\text { anxious. }\end{array}$ \\
\hline Control & $\begin{array}{l}\text { Control suggests that learners gain proficiency in the knowledge and manage to control the situations within the activities. } \\
\text { This state can contribute to learners' satisfaction with management. However, learners will feel bored if they experience an } \\
\text { excessively long control state. }\end{array}$ \\
\hline Relaxation & $\begin{array}{l}\text { Relaxation means that learners can achieve perfect control of the situations within the activities. This state enables learners to } \\
\text { rest and free from tension temporarily so that learners can prepare for the following challenging tasks. However, the } \\
\text { excessive relaxation experience will give rise to learners' indulgence in resting. }\end{array}$ \\
\hline Anxiety & $\begin{array}{c}\text { Anxiety refers to the state where the challenge level is much higher } \\
\text { learners tend to perceive great difficulty in the tasks. Excessive a } \\
\text { environment. }\end{array}$ \\
\hline Worry & $\begin{array}{l}\text { Worry stands for the state where the challenge level is moderately higher than the skill level. Notably, repeated practices } \\
\text { cannot contribute to learners' accomplishment of the tasks in the worry state. Therefore, the constant worry state will lead to } \\
\text { learners' perception of frustration or reluctance. }\end{array}$ \\
\hline Apathy & $\begin{array}{l}\text { Apathy indicates that challenge level and skill level are too low to provide learners with the opportunity of making progress } \\
\text { through practices. Learners tend to encounter few chances to improve performance or proficiency because such activities are } \\
\text { effortless. This state is the opposite concept of the flow state. }\end{array}$ \\
\hline Boredom & $\begin{array}{l}\text { Boredom reflects that learners with a particular skill level should deal with the tasks at a too low challenge level. This state } \\
\text { cannot stimulate learners' interest in extending knowledge for better proficiency or training skills for progress. }\end{array}$ \\
\hline
\end{tabular}


Notably, belief or desire to achieve specific goals can promote the process of learning [65], reflecting the significance of learning achievement in gamification learning stimulating learners'flow state. Learners show strong desire to acquire corresponding abilities for specific tasks or concepts and focus on self-improvement and development [3].

Since engagement in gamified activities requires a competitive atmosphere with the apparent goals [6], academic goals can inspire learners to achieve self-efficacy and self-regulation, contributing to academic achievement [66].

Achievements goals are usually flexible and dynamic, depending on the pedagogical contexts [3]. The dynamic setting of learning achievement goals reflects the dynamic feature of the flow state. Thus, learning achievement is consistent with learners'needs of improving involvement in optimal gamification experiences.

Additionally, motivation plays a significant role in bridging the consistency of the dynamic flow state and gamification learning. Gamification learning experiences can intrinsically and extrinsically motivate learners to reach more goals $[67,68]$.

Intrinsic motivation refers to individuals'tendency of doing specific activities for satisfaction associated with pleasure, curiosity, or interest $[3,7,65,69]$. Extrinsic motivation stands for environmental and external factors that inspire individuals to reinforce specific orientations or behaviours, including rewards, pressure, or punishment $[3,65,69]$.

Facing challenging tasks, learners tend to show curiosity to the new information and raise the awareness of making progress, reflecting the function of intrinsic motivation. The timely feedback and awards can extrinsically motivate learners to improve their skills. Therefore, motivation is a significant factor conducive to gamification learning experiences where learners can enjoy the flow state.

Therefore, the transitions among the arousal, control, and flow states can contribute to learners'optimal gamification learning. Since gamification experiences include inspiring items and goal orientations, learning achievement and motivation are the two significant factors conducive to optimal gamification learning experiences.

4.1.2. Leaners' Growth Processes Consistent with the Flow State. Since learners usually pursue progress in gamification learning, we could discuss optimal gamification learning experiences in terms of learners' growth in knowledge or skill mastery. Thus, we have introduced the Learners' Growth Model (LGM).

Learners' Growth Model (LGM) demonstrates the relation between skill development and knowledge acquisition [70]. LGM contains 20 skill and knowledge states [70].

Skill development states include nothing, rough cognitive, explanatory cognitive, associative, and autonomous stages. The rough stage stands for learners' initial input of the contents; the explanatory stage reflects learners' estimations or performance based on explanatory behaviours; the associative stage indicates that learners tend to relate skills to practices; the autonomous stage enables learners to deal with the tasks independently $[70,71]$.

Knowledge acquisition states include nothing, accretion, tuning, and restructuring stage. The accretion stage involves learners' gradual accumulation of the preexistent knowledge and the interpretation of the existing knowledge; the tuning stage enables learners to apply the knowledge to specific contexts for better understanding; the restructuring stage allows learners to extend knowledge and rebuild their current knowledge structure [70, 72].

In most cases, learners experience the changes between these states. The original LGM presents the arrows reflecting the transitions between stages. To describe the transitions straightforwardly, the researchers have used the form $S$ ( $x$, $y$ ), where $x$ stands for the skill development stage and $y$ stands for the knowledge acquisition stage [70] (see Figure 3).

Notably, learners' growth processes are compatible with the flow state [70]. Challco et al. [70] have integrated these growth processes with the flow state. The integration has suggested that the dimensions of skill development and knowledge acquisition in LGM are compatible with the skill level and correlated with the difficulty level, namely, the challenge level [70]. Since a balance between challenge level and skill level is the essential condition conducive to the flow state $[3,63]$, learners' growth processes can contribute to the flow state as the foundation for the optimal gamification learning experiences.

Moreover, the dimensions of skill development and knowledge acquisition reflect the enhancement of learning achievement. Having achieved mastery of the knowledge or skills, learners can make progress and continue learning processes based on these motivating results. The integration of LGM and the flow state demonstrates the significant roles of learning achievement and motivation in optimal gamification learning experiences.

4.1.3. Optimal Gamification Learning Experiences Based on the Integration of LGM and the Flow State. To further discuss the factors conducive to optimal gamification learning experiences, we have integrated the learners' growth process in LGM with the flow state reflecting the transition among arousal, flow, and control.

We have first integrated the dynamic flow state with the five-point-scale skill development and four-point-scale knowledge, respectively (see Figure 4). Then, we have formed a three-dimensional rectangular coordinate system consisting of the dimensions of the five-point-scale skill development, the four-point-scale knowledge acquisition, and the five-point-scale challenge level.

To investigate the distributions of the flow, arousal, and control zones in the two-dimensional LGM diagram, we have used the projections to analyze the zones that originally do not belong to the plane of the LGM diagram, namely, the skill development-knowledge acquisition rectangular coordinate system (see Figure 4). Accordingly, we have also integrated learners' growth processes with the projected zones, including overlapping zones (see Figure 4). 

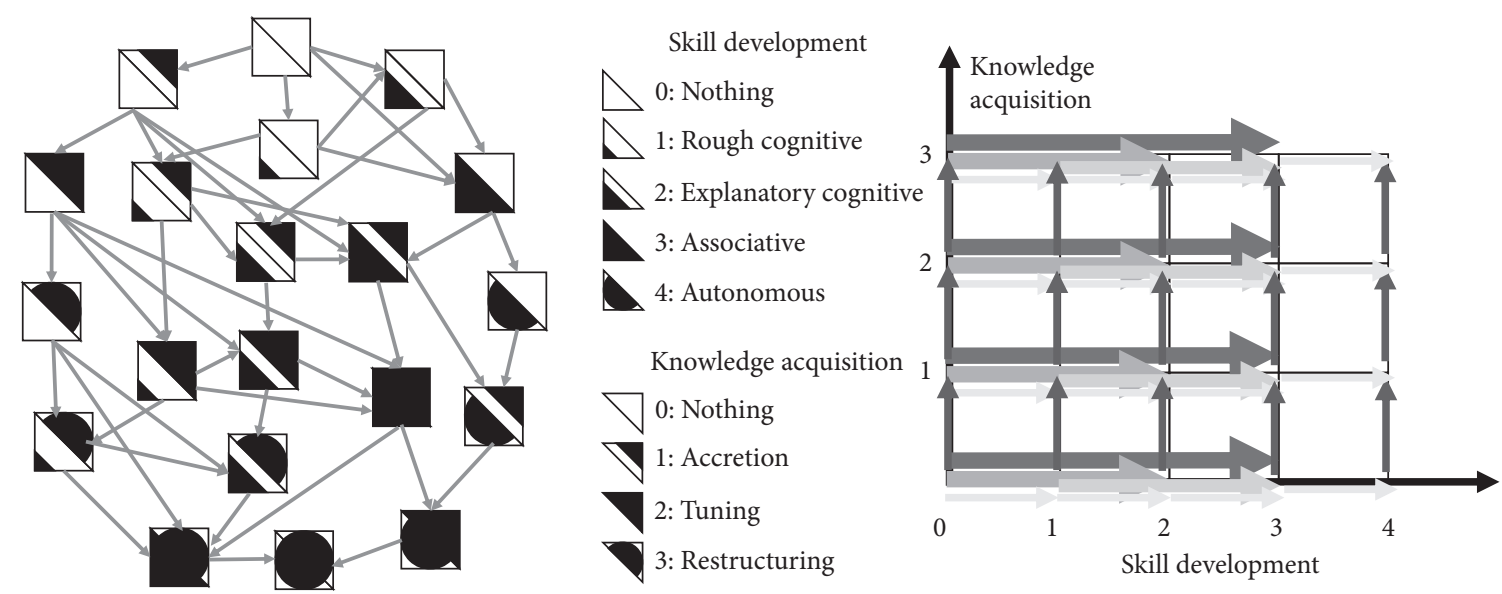

Figure 3: The Learner's Growth Model (left) $[73,74]$ and the rectangular coordinate system presenting transition between stages (right).

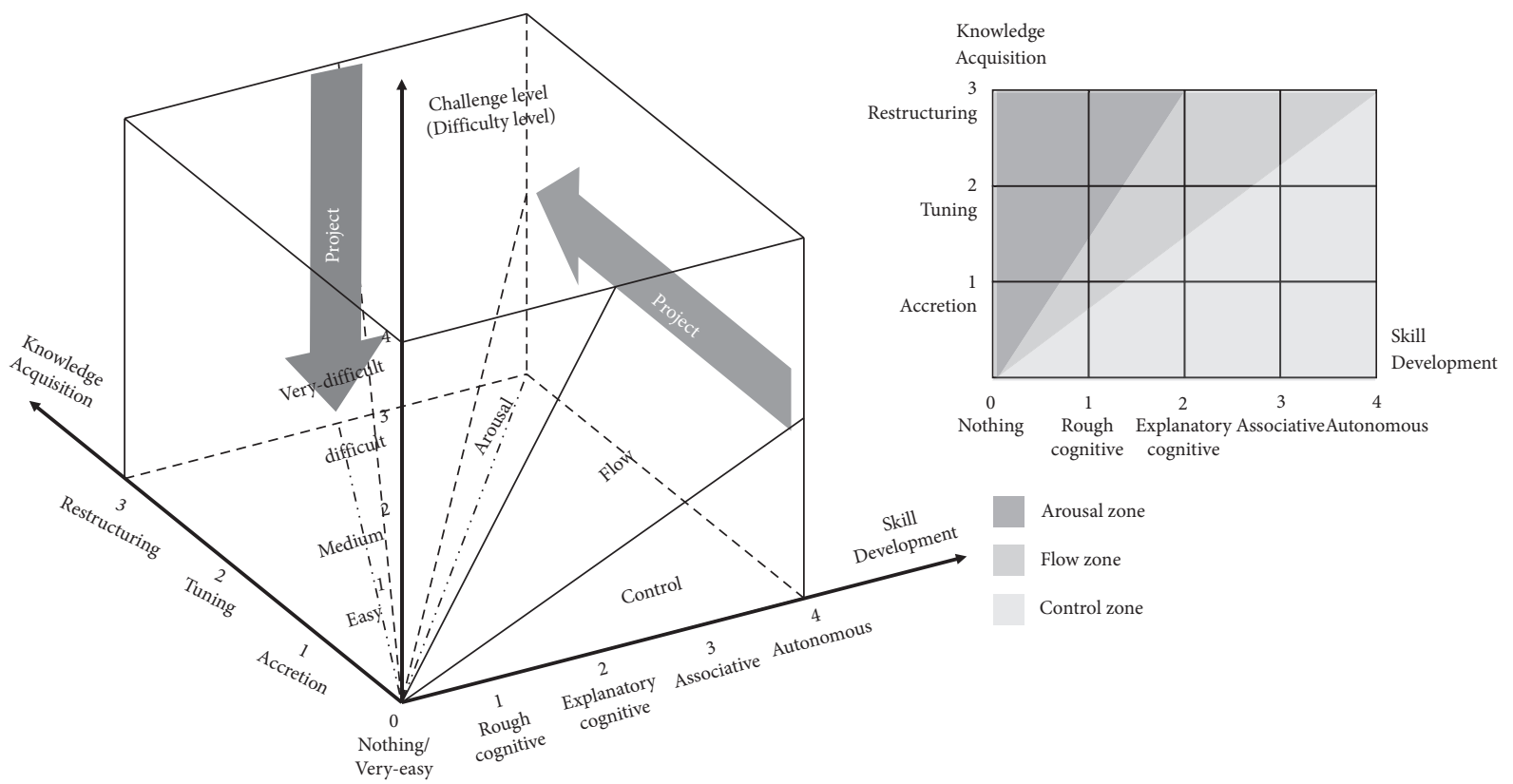

The first step of projecting:

The second step of projecting:

(a)

Figure 4: Continued. 


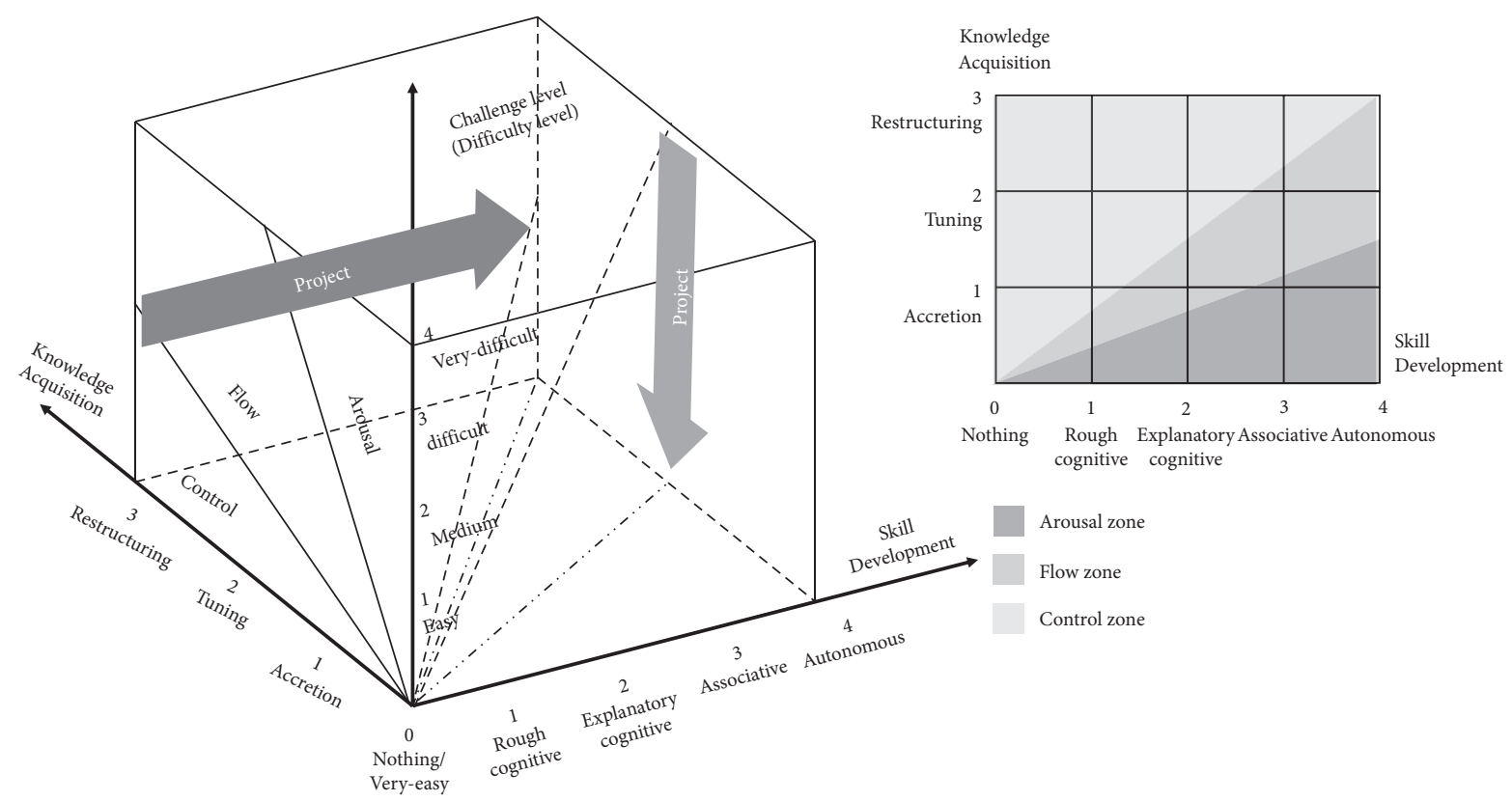

The first step of projecting:

The second step of projecting:
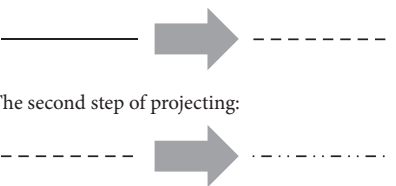

(b)

Figure 4: The integration of the Learner's Growth Model and the dynamic flow state presenting the relation between skill development and challenge level (a) and the relation between knowledge acquisition and challenge level (b).

We have followed three criteria to select the target patterns reflecting optimal learning experiences. The first criterion is that the target patterns should pass or cross the flow zone because passing or crossing the flow zone is the foundation of the transition among arousal, flow, and control.

Besides, since optimal learning experiences involve the transition among the arousal, flow, and control state [3, 64], the target learners' growth processes should contain the transition among the zones representing these states in the LGM diagram.

Moreover, optimal learning experiences require the arousal state at the beginning $[3,6,64]$. Thus, the target growth processes should intersect the flow zone, transit the arousal and control zone, and begin at the arousal zone.

Based on these three criteria, we have found five patterns representing optimal gamification learning experiences (see Figure 5). The first pattern indicates that learners have achieved the initial level of skills and attempted to accumulate the existing knowledge from the arousal state of knowledge acquisition. Then, learners tend to perceive control of the skills and achieve the flow state. The control state of knowledge acquisition reflects learners' mastery of the knowledge.

The second pattern allows learners to enhance their skills at the accretion stage. Learners at the rough cognitive level can input contents to experience the transition between the arousal state of skill development to the control state of knowledge acquisition. Having obtained enough knowledge to deal with the challenges, learners tend to enjoy the flow state and perceive control of skills.

The third pattern enables learners to experience the complete transition among arousal, control, and flow. Achieving the associative level paves the path for the common oscillation between arousal and control and the balanced flow state. Notably, this growth process can motivate learners to extend the current knowledge because learners will face more challenging knowledge tasks based on their increasing progress.

The fourth pattern demonstrates that learners will achieve the associative skill development level from the rough cognitive level. During this growth process, learners tend to progress in skill development by experiencing the control perception of knowledge acquisition and the flow state.

Like the fourth pattern, the fifth pattern empowers learners to improve their skill development by applying the accumulated knowledge to specific contexts. However, while the fourth pattern requires learners to have some skills at least at the rough cognitive level, the fifth pattern does not require learners' accumulation of skills before practices or learning. 


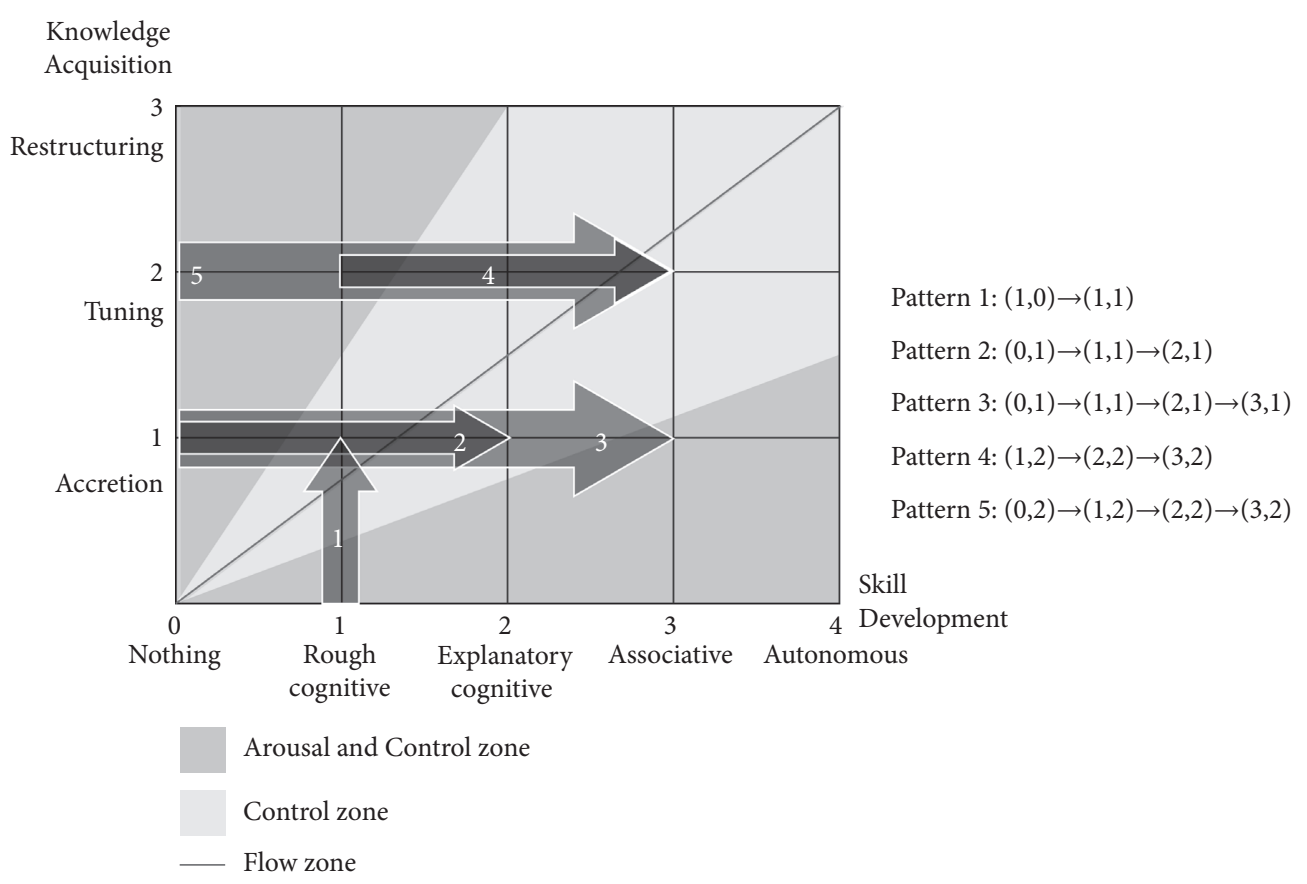

FIGURE 5: Five growth process patterns contributing to optimal gamification learning experiences.

Overall, the integration of LGM and the dynamic flow state has presented five growth process patterns representing optimal gamification learning experiences. Notably, optimal gamification learning experiences require skills at the rough cognitive, explanatory cognitive, and associative levels and knowledge at the accretion and tuning levels. Enhancement in knowledge and skills represent learning achievement; learners can achieve motivation when experiencing growth in learning based on the dynamic balance between challenges and skills.

In summary, this part describes the role of learning achievement and motivation in optimal gamification learning experiences and the conditions conducive to these experiences. The flow theory, LGM, and the integration of them have presented the significance of learning achievement and motivation. Therefore, we can conclude that learning achievement and motivation can contribute to optimal gamification learning experiences. The five growth process patterns are the conditions of these experiences.

\subsection{Can Gamification Platforms including Classcraft Positively} Influence Learning Achievement and Motivation for Optimal Gamification Learning Experiences? Since learning achievement and motivation are the factors conducive to optimal gamification learning experiences, we have conducted a meta-analysis examining the effects of gamification platforms including Classcraft on these two factors. Positive effects on learning achievement and motivation suggest that these platforms can create optimal gamification learning experiences. We have input the dataset of the 27 studies (see Table 2) in the STATA 15 platform and have gained the following results.
4.2.1. Basic Analysis Examining the Overall Effects on the Factors Conducive to Optimal Gamification Learning Experiences. According to the heterogeneity test of the dataset, we have obtained the parameters of $I^{2}=87.1 \%$, Cochran's $Q=262.73$, and $p<0.05$, reflecting significant heterogeneity in this dataset. Accordingly, we have used the random-effects model to investigate the effects of gamerelated pedagogical models on learning achievements.

Regarding the overall effects on learning achievements (see Figure 6), the random-effects model has demonstrated a significant effect $(d=0.613, z=8.682, p<0.05,95 \%$ CI $[0.474,0.751])$, reflecting the overall positive effects of the gamification platforms on learning achievement and motivation. Thus, gamification platforms including Classcraft can create conditions for optimal learning experiences.

4.2.2. Subgroup Analysis Comparing the Effects on Learning Achievement and Those on Motivation. We have conducted the subgroup analysis to compare the effects of gamification platforms including Classcraft on factors conducive to optimal gamification learning experiences. According to the subgroup analysis results (see Figure 6), the learning achievement subgroup has the following results: $d=0.621$, $z=5.846, p<0.05,95 \%$ CI $[0.413,0.829]$; the motivation subgroup has the following results: $d=0.608, z=6.167$, $p<0.05,95 \%$ CI $[0.415,0801]$. The results have revealed that both subgroup analyses have statistical significance $(p<0.05)$ and that gamification platforms including Classcraft exert similarly positive effects on learning achievement and motivation.

Regarding subgroup heterogeneity, two subgroups have relatively high heterogeneity $(p<0.05)$ but relatively low heterogeneity between groups $(p=0.929>0.05)$. The 


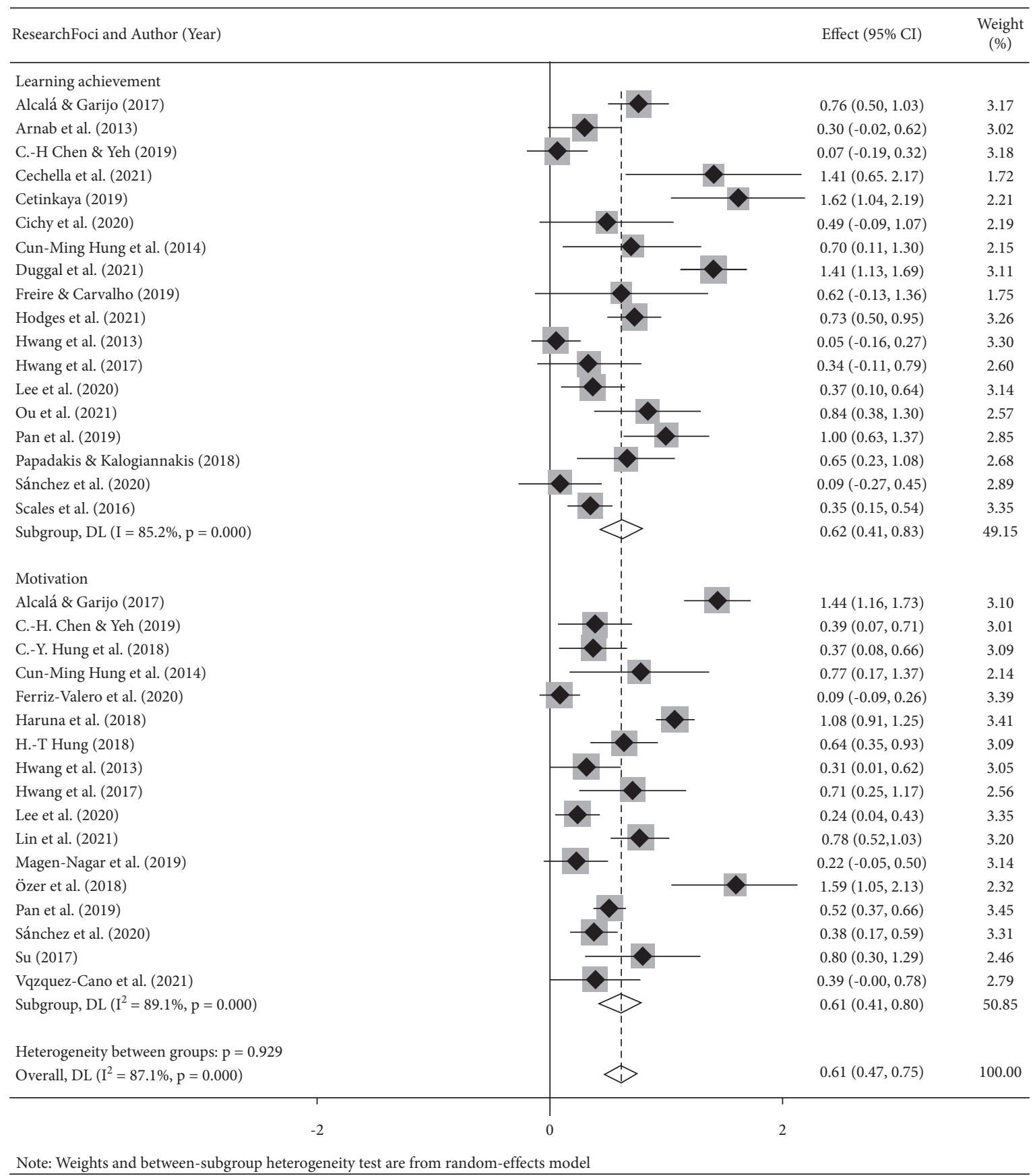

FIGURE 6: Forest plots presenting the effects of gamification platforms including Classcraft on learning achievement and motivation contributing to optimal gamification learning experiences.

heterogeneity in the learning achievement subgroup $\left(I^{2}=85.2 \%, p<0.05\right)$ is lower than that in the serious game subgroup $\left(I^{2}=89.1 \%, p<0.05\right)$.

Overall, the gamification platforms including Classcraft have similarly positive effects on learning achievement and motivation. Positive effects on these two factors can contribute to optimal gamification learning experiences. Thus, gamification platforms including Classcraft can fulfil the conditions for optimal gamification learning experiences.
4.2.3. Tests Examining Heterogeneity Factors and Publication Bias. To investigate the potential sources of heterogeneity, we have conducted the meta-analysis regression to analyze the potential variables influencing the heterogeneity. We have set the following variables: year (the publication year), foci (the research foci: 1=learning achievement, $2=$ motivation), En (the number of the experimental group participants), Em (the mean of the experimental group participants' target items), Esd (the standard deviation of the 
statistical findings in the experimental group), $\mathrm{Cn}$ (the number of the experimental group participants), $\mathrm{Cm}$ (the mean of the control group participants' target items), and Csd (the standard deviation of the statistical findings in the control group).

According to the regression analysis results (see Table 4), $\operatorname{Em}(p=0.004<0.05)$ and $\operatorname{Cm}(p=0.009<0.05)$ are the potential factors contributing to the heterogeneity. Since different studies have different scales to participants' target item, different studies accordingly demonstrate different criteria involving various kinds of mean, reflecting the rationality of using SMD in turn.

We have investigated the significantly influential studies through the sensitivity analysis. The sensitivity analysis results (see Figure 7) have demonstrated that the studies of Haruna et al. [47] and Ferriz-Valero et al. [46] have contributed relatively the most influences to the overall effects.

Considering publication bias, Egger's test results (see Table 5) have revealed that there is no obvious publication bias $(p=0.143>0.1)$. The funnel plot (see Figure 8 ) has not presented excessive asymmetries except for some dots representing very significant effects. Since trim-and-fill analysis has remained this set of data unchanged, the effects on motivation have statistical significance.

In summary, this part describes the effects of gamification platforms including Classcraft on learning achievement and motivation, the factors conducive to optimal learning experiences. The results have demonstrated similarly positive effects on learning achievement and motivation. Without significant publication bias, we can conclude that gamification designs including Classcraft can positively influence learning achievement and motivation for optimal gamification learning experiences.

4.3. Can Classcraft Fulfil the Conditions of Optimal Gamification Learning Experiences to Positively Influence Learning Achievement and Motivation? The meta-analysis has demonstrated that gamification platforms including Classcraft can fulfil the conditions of optimal gamification learning experiences. The integration of LGM and the dynamic flow state has presented that skill development at the rough, explanatory, and associative levels and knowledge acquisition at the accretion and tuning levels can contribute to optimal gamification learning experiences. Then, we have explicitly concentrated on Classcraft and discussed whether Classcraft can fulfil the previous conditions to create optimal learning experiences.

4.3.1. Classcraft Reward and Penalty Systems Reflecting Rough Cognitive, Explanatory Cognitive, and Associative Skill Development. Classcraft transforms the pedagogical practices into a role-playing scenario where learners have various skills and bear corresponding responsibilities $[11,12,32]$. Classcraft involves unique reward and penalty systems that turn learners' mastery of knowledge or skills into several kinds of points $[15,34,75]$. Facing these motivating settings of points, learners can foster the strategic skills to guarantee the long-term accomplishment of tasks $[15,75]$.

The reward and penalty system involves Experience Points (XP), Health Points (HP), Action Points (AP), and Power Points (PP) for learners' success in the gamified world $[11,12]$. Experience Points (XP) enable learners to level up and unlock powers to deal with high-levelled challenges. XP motivate learners to perform positive behaviours such as correctly answering a question, helping others with their work, or keeping hard-working in class $[11,12]$.

Health Points (HP) reflect learners' active conditions in gamified activities. Negative behaviours such as interrupting the class or failing to submit the assignments on time lead to losses in HP as penalties. When learners have reached $0 \mathrm{HP}$, they fail in the game and receive a sentence $[10,11]$.

Action Points (AP) indicate the limitations on learners' uses of powers. AP decreases each time learners' use powers to perform the characters' skills. Learners can gain AP automatically each day, and instructors can modify the amount of AP. The setting of AP inspires learners to make full use of characters' powers to accomplish long-term goals $[11,12]$.

Power Points (PP) enable learners to unlock powers. Characters' basic, medium, and advanced powers cost $1 \mathrm{PP}$, $2 \mathrm{PP}$, and $3 \mathrm{PP}$, respectively. Although learners can gain considerable powers, Classcraft still allows instructors to unlearn specific powers and return PP to the learners to narrow the gap between learners $[11,12,27]$.

Motivated by the mechanics based on points for rewards and penalties, learners can emphasize progress in learning [46]. The game mechanics based on points attract learners to begin learning processes in the gamified world, reflecting rough cognitive skill stage because of the initial understanding of the target skill $[70,71]$.

As learners gradually differentiate characters' features and behaviours, they tend to establish basic preferences of powers or strategies and select the desired skills based on estimations $[14,34]$. The process of considering the efficient strategies or approaches to achieve goals can enhance learners' awareness of interpretation or evaluation, reflecting learners' explanatory cognitive skill $[14,70,71]$.

The setting of teams in Classcraft enables learners to consider their behaviours in the long term. Learners can summarize the current results and implement long-term plans for academic success $[14,15,33,34,75]$. Individual or team practices based on the mechanics of points can motivate learners to relate skills development to learning practices, accounting for the consistency with the associative skill stage [70, 71].

Thus, the unique reward and penalty system based on points can fulfil the conditions of skill development at the rough cognitive, explanatory cognitive, and associative levels. The gamified world can create entertaining learning environments and inspire learners to refine their approaches to academic success.

4.3.2. Classcraft Gamified Interaction and Collaboration Designs Reflecting the Accretion and Tuning Knowledge Acquisition. Classcraft provides gamified activities 
TABLE 4: Metaregression results presenting the potential factors contributing to heterogeneity.

\begin{tabular}{|c|c|c|c|c|c|c|}
\hline _ES & Coef. & Std. err. & $t$ & $P>t$ & \multicolumn{2}{|c|}{$[95 \% \mathrm{CI}]$} \\
\hline year & -0.006479 & 0.0274077 & -0.24 & 0.815 & -0.0628163 & 0.0498584 \\
\hline foci & 0.088852 & 0.1541811 & 0.58 & 0.569 & -0.2280718 & 0.4057758 \\
\hline En & 0.0009369 & 0.002554 & 0.37 & 0.717 & -0.004313 & 0.0061868 \\
\hline $\mathrm{Em}$ & 0.0824363 & 0.0263825 & 3.12 & 0.004 & 0.0282062 & 0.1366663 \\
\hline Esd & -0.0306149 & 0.0482229 & -0.63 & 0.531 & -0.1297386 & 0.0685088 \\
\hline $\mathrm{Cn}$ & -0.0010384 & 0.0029291 & -0.35 & 0.726 & -0.0070593 & 0.0049824 \\
\hline $\mathrm{Cm}$ & -0.0783375 & 0.0276122 & -2.84 & 0.009 & -0.1350952 & -0.0215797 \\
\hline Csd & -0.0184393 & 0.0511009 & -0.36 & 0.721 & -0.1234786 & 0.0866001 \\
\hline _cons & 13.49913 & 55.2608 & 0.24 & 0.809 & -100.0911 & 127.0893 \\
\hline
\end{tabular}

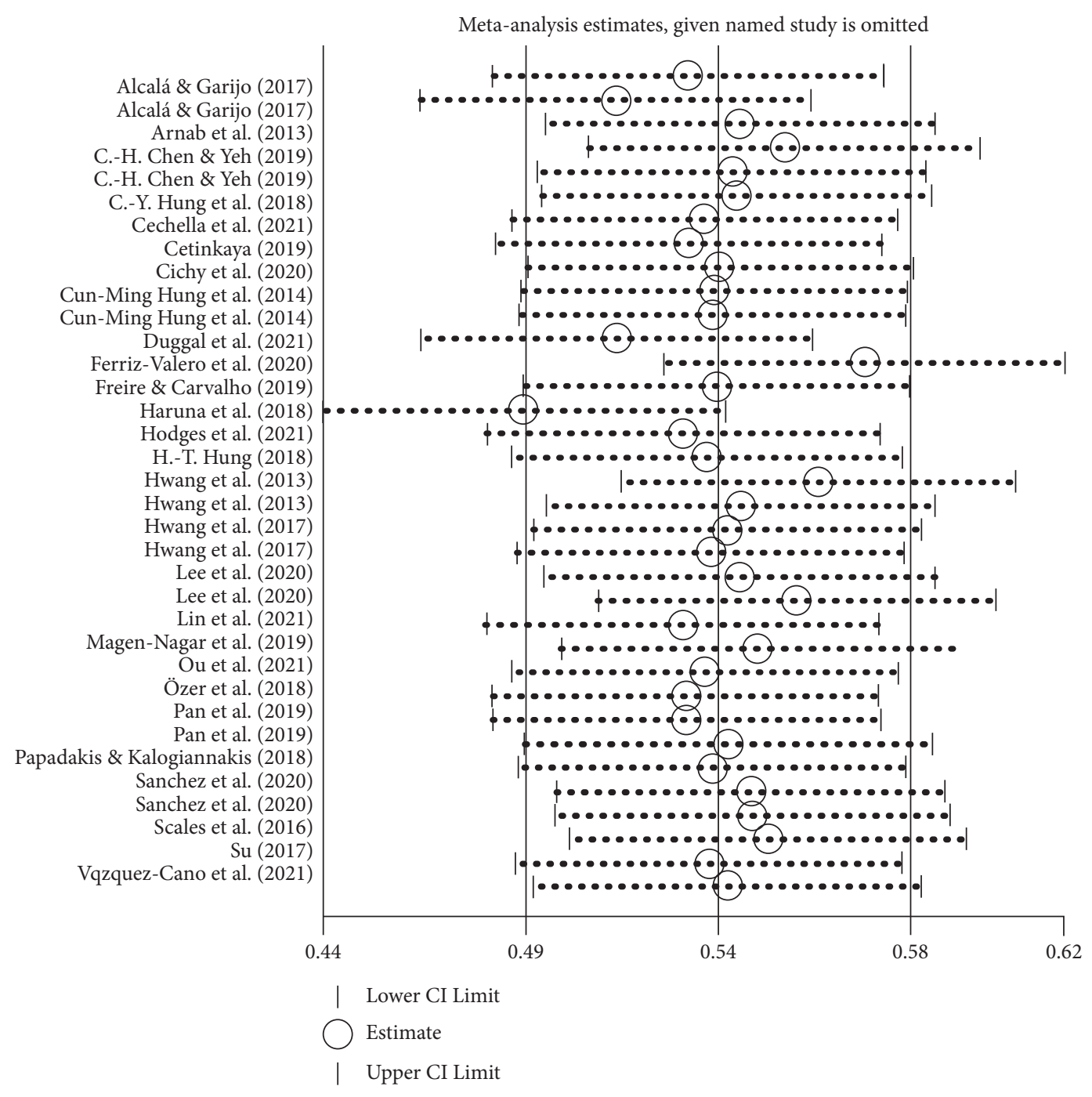

FIgURE 7: The sensitivity analysis examining the influential components in the data.

TABLE 5: Egger's test results presenting publication bias in the data.

\begin{tabular}{|c|c|c|c|c|c|c|}
\hline Std_Eff & Coef. & Std. err. & $t$ & $P>t$ & \multicolumn{2}{|c|}{$[95 \% \mathrm{CI}]$} \\
\hline Slope & 0.3031996 & 0.1689772 & 1.79 & 0.082 & -0.0405871 & 0.6469862 \\
\hline Bias & 1.782734 & 1.187503 & 1.50 & 0.143 & -0.6332592 & 4.198728 \\
\hline
\end{tabular}




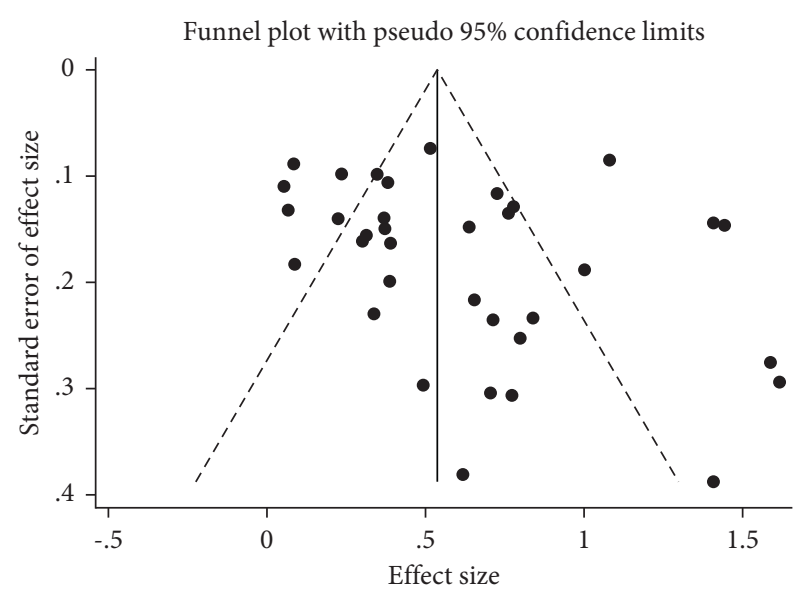

Figure 8: The funnel plot of the data in the meta-analysis.

involving interaction between instructors and learners and collaboration among learners, contributing to enhancement in knowledge mastery [10-12]. These interaction and collaboration designs are consistent with knowledge acquisition at the accretion and tuning levels.

Classcraft involves flexible designs to ensure the interaction between instructors and learners [27]. Instructors enjoy much freedom to create gamified learning environments accustomed to the pedagogical contexts [29]. Instructors can also adjust class settings, such as the course languages and presentation of scores tailored to learners' preferences $[11,12]$.

Flexible and various in-class activities in the gamified experiences can also ensure interaction in Classcraft. The reward or penalty system based on points encourages learners to perform the desired behaviours [28, 31, 46, 76]. Instructors can constrain or reinforce learners' specific behaviours $[11,12,28,35]$. The activity of Wheel of Destiny involves random roll calls to improve learners' attention and guarantee a vibrant and dynamic in-class atmosphere $[11,12]$. The activity of Riders of Vay involves a series of random events associated with rewards or penalties of points $[11,12]$. Based on these flexible in-class activities, instructors can modify the events to balance the unpredictability and difficulty of the course for learners' better experiences $[33,35]$.

Additionally, flexible and user-friendly feedback in Classcraft ensures the interaction between instructors and learners [76]. Classcraft offers a messaging platform facilitating the sharing of information and feedback [11, 12]. Timely feedback reflects the evaluation of the current gamified learning experiences where instructors and learners can make corresponding adaptations in learning strategies or pedagogical practices [10].

Thus, flexible in-class designs in Classcraft guarantee the interaction between instructors and learners. Freedom of design in the gamified experiences enables instructors to consider learners' significant role in the whole classes $[11,12]$. The reward and penalty system inspires learners to accumulate the target knowledge $[35,46,76,77]$. In-class activities involving random events motivate learners to consolidate the application of knowledge to the gamified pedagogical circumstances $[10,12,31]$. Classcraft interaction designs encourage learners to accumulate and apply knowledge [35, 70, 72, 77], reflecting learners' knowledge acquisition at the accretion and tuning knowledge levels.

The collective designs in Classcraft ensure collaboration among learners. Classcraft offers collaborative learning tasks that inspire learners to emphasize collective efforts $[29,30,33]$. Individual behaviours can influence the team members' conditions [11, 12]. Having assigned teammates with specific roles or behaviours, learners can accumulate and use knowledge oriented to academic success $[10,12,30,35,77]$.

Notably, the collective activities in Classcraft are personalized and motivating for learners' awareness of making progress [25, 26]. Classcraft provides self-paced learning platforms tailored to learners' learning habits and current mastery of knowledge [3,10]. During the gamified experiences in Classcraft, learners gain points depending on progress in mastery of the target knowledge and quality of submitted tasks $[11,12]$.

Thus, collective tasks in Classcraft guarantee the collaboration among learners. Since individuals' behaviours might influence the advance of the whole teams, learners can hold a more prudent attitude to comprehending and utilizing knowledge for individual and team accomplishments $[11,12]$. Based on the collective orientation to academic success, learners can reach accumulation and tuning knowledge levels.

Classcraft can also positively influence learners' learning achievement and motivation. The fulfilled conditions of skill development and knowledge acquisition that Classcraft can enhance learners' learning achievement. Flexible in-class activities and settings including game mechanics based on points, random event tasks, and self-paced collaborative activities in Classcraft can ensure learners' motivation in gamification learning experiences.

In summary, Classcraft can fulfil the conditions of skill development at the rough cognitive, explanatory cognitive, and associative levels and knowledge acquisition at the accretion and tuning levels. These factors can contribute to optimal gamification learning experiences involving the enhancement in learning achievement and motivation. Therefore, we can conclude that Classcraft can fulfil the conditions of optimal gamification learning experiences to positively influence learning achievement and motivation.

\section{Discussion}

This section describes potential reasons for the positive effects of gamification platforms on learning achievement and motivation conducive to optimal learning experiences. This section also presents the implications of using gamification platforms in pedagogical practices.

5.1. Potential Reasons Contributing to the Positive Effects on Learning Achievement and Motivation. Considering the factor conducive to positive effects on learning achievement, 
fun plays an essential role. Games can create fun and playful experiences that enhance learners' participation in the target activities and make academic progress [78]. Fun refers to a social-emotional interactive process [79] and a subset of enjoyment [80]. In educational areas, fun can provide positive emotional or psychological states encouraging individuals to spontaneously and enjoyably participate in the activities [3].

Motivation plays an essential role in gamification success, suggesting that gamification platforms highlight the cultivation of motivation [69]. Indeed, gamification has more positive effects on extrinsic motivation than intrinsic motivation [3].

The first potential reason for the relatively significant effects on extrinsic motivation lies in the controllable nature of extrinsic conditions. Extrinsic motivation is associated with environmental and external factors, such as rewards, pressure, or punishment, while intrinsic motivation is related to inherent reactions, such as pleasure, curiosity, or interest [3].

Notably, not all individuals can achieve intrinsic motivation in specific learning due to the abstract nature and inherent effects, while most individuals can achieve motivation from the relatively controllable external factors [3]. For that reason, some educators tend to pay attention to the external factors to stimulate learners' interest and use strategies to enhance their extrinsic motivation [3].

Besides, educators tend to pay more attention to extrinsic motivation because gamification platforms can enhance learners' intrinsic motivation based on extrinsic motivation [3]. Individuals can simultaneously achieve intrinsic and motivation [68]. Extrinsic motivation plays an indispensable role in game-related pedagogies because when the environmental or external factors do not meet the demand of involvement, learners are not likely to achieve any motivation [3].

Thus, educators tend to use rewards or punishments, the external factors, to extrinsically and intrinsically motivate learners [3]. However, educators should notice how they use the external stimuli because excessive extrinsic motivation will negatively influence intrinsic motivation [81].

Moreover, considering the features of games, games can provide various external stimuli [3]. Kim et al. [3] have argued that goals, rules, and interactions are the standard game characteristics associated with extrinsic motivation. Thus, games can present desired sparable outcomes, the autonomy of behaviours, and reciprocal actions involving competition, feedback, perception, and results [3] consistent with the conditions of extrinsic motivation [65].

Overall, game implementation in pedagogical practices can create fun experiences that stimulate learners' interest in learning and enhance learning achievement and motivation. Controllability of external factors, an association between extrinsic and intrinsic motivation, and external stimuli as the distinctive feature of games suggests that gamification platforms emphasize the cultivation of extrinsic motivation.
5.2. Game-Related Approaches Implying Preferences for Well-Being. The entertaining and exciting atmosphere accounts for the incredible popularity of gamified designs in educational contexts [3]. Even if the pandemic disease limits education with close contact to some extent, learners still have desires for joyful experiences [82]. Implementing games or game elements implies learners' preference for well-being in pedagogical practices [1].

In educational contexts, the preference for fun experiences during pedagogical practices reflects the pursuit of well-being [1]. Education is associated with well-being because education can make learners' lives more fulfilling and meaningful [83]. To fulfil the conditions of well-being in pedagogical practices, educators can combine objective research on subjects with researches on the subjective factors that can motivate and sustain learners' interest in learning [1].

However, excessive emphases on personal well-being might diminish the influence and importance of subjectspecific knowledge, alter instructors' understanding about the relation with learners [84], and distract learners from democratic citizenship [85]. For that reason, the cultivation of learners' well-being should be in line with the specific principles.

Dewey [86] has proposed the principles of continuity and interaction to enhance learners' sense of well-being. Continuity reflects rich and fluid learning processes that refine learners' initial perceptions [86]. Interaction requires the combination of objective learning processes and learners' subjective conditions, such as learners' emotional reactions or mental mapping of the learning contents [86]. That combination can improve the meaningfulness of learning [87].

Apart from Dewey's [86] two principles, openness in learning environments can contribute to learners' sense of well-being by enhancing the cooperative relation between instructors and learners [1]. For instructors, openness can exemplify instructors' virtues and extended opportunities for exercising reflection and deliberation [88]. For learners, openness can contribute to learners' active and critical thinking [1]. Openness can facilitate interactions between instructors and learners and prevent excessively didactic teaching, insufficiently informed learning experiences, or distraction from instructors' role in making professional judgments [1].

Thus, gamification implies learners' preference for wellbeing in joyful experiences. Since the implementation of games in practices can create enjoyable learning experiences, learners can perceive well-being that stimulates their positive attitudes to pedagogical practices. Continuity, interaction, and openness are the three factors conducive to learners' sense of well-being.

Classcraft can fulfil these factors conducive to well-being. Classcraft ensures the continuity of gamified activities by enabling users to adjust the class settings to current contexts $[11,12]$. Classcraft involves the team and character elements that can stimulate learners' interest in strategic collaboration with other learners and interaction with instructors $[11,12]$. Flexible self-paced learning designs in 
Classcraft contribute to open gamification learning environments $[11,12]$.

Overall, continuity, interaction, and openness are conducive to learners' perception of well-being in pedagogical practices. Classcraft can fulfil the conditions of these factors, reflecting the efficiency of this platform. Indeed, although well-being can relatively influence learning, instructors should highlight well-being to an appropriate degree during pedagogical practices.

\section{Conclusion}

This section describes the main conclusions of the research questions. Admittedly, this study has some limitations that can present insights for future researches.

6.1. Major Findings. RQ1 focuses on the role of learning achievement and motivation in optimal gamification learning experiences. The optimal mental state requires dynamic transitions among arousal, control, and flow. Since LGM also presents learners' overall transition between knowledge and skill stages, we have integrated LGM with the dynamic flow state to investigate the conditions conducive to optimal learning experiences. Integration results have demonstrated that five patterns associated with learning achievement and motivation. Therefore, the main conclusion of this question is that learning achievement and motivation can contribute to optimal gamification learning experiences.

RQ2 concentrates on the effects of gamification platforms including Classcraft on learning achievement and motivation. According to the meta-analysis, the gamification platforms including Classcraft can overall enhance gamification learning experiences $(d=0.613, z=8.682, p<0.05,95 \% \mathrm{CI}$ $[0.474,0.751])$. According to the subgroup analysis, the effects on learning achievement $(d=0.621, z=5.846, p<0.05,95 \%$ CI $[0.413,0.829])$ are similar to those on motivation $(d=0.608, z=6.167, p<0.05,95 \%$ CI $[0.415,0801])$. Without significant publication bias $(p=0.143>0.1)$, the results have demonstrated that gamification platforms including Classcraft can create optimal learning experiences by similarly enhancing learning achievement and motivation. Therefore, the main conclusion of this question is that gamification platforms including Classcraft can positively influence learning achievement and motivation for optimal gamification learning experiences.

RQ3 describes whether Classcraft can fulfil the conditions of optimal gamification learning experiences to enhance learning achievement and motivation. We have summarized five stages conducive to optimal learning experiences: skill development at the rough cognitive, explanatory cognitive, and associative levels and knowledge acquisition at the accretion and tuning levels. The unique reward and penalty systems based on points, powers, or behaviours and gamified activities involving interactions and collaborations can fulfil these conditions. These conditions are also consistent with learners' enhancement in learning achievement and motivation. Therefore, the main conclusion of this question is that Classcraft can fulfil the conditions of optimal gamification learning experiences to positively influence learning achievement and motivation.

We have also discussed the potential reasons conducive to the positive effects of gamification platforms on learning achievement and motivation. Fun experiences and the controllability of external stimuli can potentially contribute to the positive influences of gamification designs. Besides, the implementation of game designs implies learners' preference for well-being in pedagogical practices. Continuity, interaction, and openness can create gamification learning processes stimulating learners' perception of wellbeing. Classcraft can fulfil these conditions to create joyful and efficient gamification learning processes.

In conclusion, Classcraft can create optimal gamification learning processes positively associated with learning achievement and motivation. Driven by the motivating tasks and activities in Classcraft, learners can achieve great engagement in the gamified experiences and reach learning goals with an increasing level of challenges.

\subsection{Limitations of This Study and Insights for Future Research} Studies. Admittedly, this study still has some limitations. The major limitation lies in the coverage of the studies. We may probably have failed to find some valuable studies due to the limited availability of the sources. It would be greatly appreciated if the readers could provide more related studies to extend and diversify the results of this study.

Besides, the relatively high heterogeneity among the extracted studies is another limitation of this study. Due to the diversity in experimental procedures, we have used the random-effects models to conduct meta-analysis. However, a limited heterogeneity among the studies can decrease research errors and provide more persuasive results concerned with the effects of game-related pedagogical models on learning achievement and motivation.

Furthermore, some concepts such as mental states, skill development, or knowledge acquisition are susceptible to external factors. Although gamification designs positively influence learners' mental states, skill development, and knowledge acquisition, learners' self-discipline, peer pressure, or spatial conditions may influence these effects.

These points provide the following insights for future researches. We can expand the research coverage to balance the heterogeneity. Future research could explore the effects of eight mental states in the flow model on gamification learning. Researchers could investigate the correlation among mental states, skill development, and knowledge acquisition based on the use of Classcraft in occupational training contexts.

\section{Data Availability}

All data and materials used support the published claims and comply with field standards.

\section{Conflicts of Interest}

The authors declare that they have no conflicts of interest regarding the publication of this study. 


\section{Authors' Contributions}

Qi Zhang performed conceptualization, methodology, investigation, writing of the original draft; Liheng Yu took part in investigation, writing-review \& editing of the manuscript; Zhonggen $\mathrm{Yu}$ involved in supervision, writing-review \& editing of the manuscript, and was responsible for funding acquisition.

\section{Acknowledgments}

This work was supported by the Fundamental Research Funds for the Central Universities, and the Research Funds of Beijing Language and Culture University (grant number: 21YCX047), 2019 MOOC of Beijing Language and Culture University (grant number: MOOC201902), Research and Reform of the "Undergraduate Teaching Reform and Innovation Project" of Beijing Higher Education in 2020-Innovative "Multilingual +" Excellent Talent Training System-(grant number: 202010032003).

\section{References}

[1] M. Thorburn, "Personal well-being and curriculum planning: a critical comparative review of theory, policy and practice coherence," Educational Review, vol. 12, pp. 1-15, 2018.

[2] D. R. Isbell and B. Kremmel, "Test review: current options in at-home language proficiency tests for making high-stakes decisions," Language Testing, vol. 37, no. 4, pp. 600-619, 2020.

[3] S. Kim, K. Song, B. Lockee, and J. Burton, Gamification in Learning and Education: Enjoy Learning like Gaming, Springer International Publishing AG, Cham, Switzerland, 2018.

[4] T. Fullerton, Game Design Workshop: A Playcentric Approach to Creating Innovative Games, CRC Press, Boca Raton, FL, USA, 2nd edition, 2008.

[5] F. Groh, "Gamification: state of the art definition and utilization," in Proceedings of the $4^{\text {th }}$ Seminar on Research Trends in Media Informatics, N. Asaj, K. Bastian, M. Poguntke, F. Schaub, B. Wiederschiem, and M. Weber, Eds., pp. 39-45, Institute of Media Informatics Ulm University, Ulm, Germany, 2012.

[6] L. C. Vieira and F. S. Corrêa da Sliva, Understanding Fun, Paper presented at Videojogos 2014, Barcelos, Portugal, 2014.

[7] Z. Yu, "Indicators of satisfaction in clickers-aided EFL class," Frontiers in Psychology, vol. 6, p. 587, 2015.

[8] Z. Yu, M. Gao, and L. Wang, "The effect of educational games on learning outcomes, student motivation, engagement and satisfaction," Journal of Educational Computing Research, vol. 0, no. 0, pp. 1-23, 2020.

[9] R. Hu and J. Shang, "Application of gamification to blended learning in elementary math instructional design," in Blended Learning: Enhancing Learning Success, S. K. S. Cheung, Ed., Springer International Publishing, Cham, Switzerland, pp. 93-104, 2018.

[10] E. Sánchez, S. Young, and C. Jouneau-Sion, "Classcraft: from gamification to ludicization of classroom management," Education and Information Technologies, vol. 22, no. 2, pp. 497-513, 2017.

[11] I. Rivera-Trigueros and M. d. M. Sánchez-Pérez, "Classcraft as a resource to implement gamification in English-medium instruction," in Teacher Training for English-medium
Instruction in Higher Education, M. M. Sánchez-Pérez, Ed., IGI Global, Hershey, PA, USA, 2020.

[12] I. Rivera-Trigueros and M. M. Sánchez-Pérez, "Conquering the iron throne: using Classcraft to foster students' motivation in the EFL classroom," Teaching English with Technology, vol. 20, no. 2, pp. 3-22, 2020.

[13] Classcraft.com, Classcraft to be Honored at 2018 EdTech Innovation Showcase at the Education Business Forum in New York, https://www.classcraft.com/press/edtech-innovationshowcase, 2018.

[14] D. A. Haris and E. Sugito, "Analysis of factors affecting user acceptance of the implementation of ClassCraft e-Learning: case studies faculty of information technology of Tarumanagara university," in Proceedings of the 2015 International Conference on Advanced Computer Science and Information Systems (ICACSIS), pp. 73-78, IEEE, Depok, Indonesia, October 2015.

[15] D. S. Freire and A. A. Carvalho, "Classcraft: a aprendizagem que se transforma num desafio permanente!" Revista Intersaberes, vol. 14, no. 31, pp. 58-74, 2019.

[16] M. Sailer and L. Homner, "The gamification of learning: a meta-analysis," Educational Psychology Review, vol. 32, no. 1, pp. 77-112, 2020.

[17] S. Boller, Game Based Learning: Why does it Work? BLP NewsLessons on Learning Blog, https://www. bottomlineperformance.com/gamebasedlearning/\#_edn2, 2012.

[18] A. I. Wang, M. Zhu, and R. Sætre, "The effect of digitizing and gamifying quizzing in classrooms," in European Conference on Games Based LearningAcademic Conferences and Publishing International, Paisley, Scotland, 2016.

[19] S. Deterding, R. Khaled, L. E. Nacke, and D. Dixon, "Gamification: toward a definition," in CHI 2011 Gamification Workshop ProceedingsACM Press, New York, NY, USA, 2011.

[20] A. Matallaoui, N. Hanner, and R. Zarnekow, "Introduction to gamification: foundation and underlying theories," in Gamification: Using Game Elements in Serious Contexts, S. Stieglitz, C. Lattemann, S. Robra-Bissantz, R. Zarnekow, and T. Brockmann, Eds., Springer, Cham, Switzerland, 2017.

[21] R. Caillois, Man, Play, and Games, University of Illinois Press, Chicago, IL, USA, 1961.

[22] K. Salen and E. Zimmermann, Rules of Play: Game Design Fundamentals, MIT Press, Cambridge, MA, USA, 2004.

[23] J. McGonigal, Reality Is Broken: Why Games Make Us Better and How They Can Change the World, Penguin, London, UK, 2011.

[24] M. Oliveira and S. Petersen, "The choice of serious games and gamification," in Serious Games Development and Applications, M. Ma, M. F. Oliveira, and J. Baalsrud Hauge, Eds., Springer, Cham, Switzerland, 2014.

[25] S. Sipone, V. Abella-García, M. Rojo, and L. dell’Olio, "Using ClassCraft to improve primary school students' knowledge and interest in sustainable mobility," Sustainability, vol. 13, no. 17, p. 9939, 2021.

[26] R. Poy and M. García, "Wizards, elves and orcs going to high school: how role-playing video games can improve academic performance through visual learning techniques," Education for Information, vol. 35, no. 3, pp. 305-318, 2019.

[27] W. Bretherton, G. Sim, and J. C. Read, "Classcraft in the primary school classroom," in Proceedings of the 10th European Conference on Games Based Learning, T. Connolly and L. Boyle, Eds., pp. 67-74pp. 67-, England, UK, October 2016.

[28] C. Garcia-Garcia, J. G. Serrano, and R. I. Escrig, "Application of Project based learning and gamification methodologies as 
motivationa tolos for students," in Proceedings of the INTED2016: 10th International Technology, Education and Development Conference, L. G. Chova, A. L. Martinez, and I. C. Torres, Eds., pp. 3241-3250, Valenica, Spain, March 2016.

[29] G. Bovin and E. Sanchez, "Social engagement in a digital roleplaying game dedicated to classroom management," in Proceedings of the International Conference on Games and Learning Alliance. GALA 2017: Games and Learning Alliance, J. Dias, P. Santos, and R. Veltkamp, Eds., pp. 137-147, Lisbon, Portugal, December 2017.

[30] M. Ceballos and L. Parody, "Gamification influence: a case study of a mathematics course at the Universidad Loyola Andalucia," in Proceedings of the 11th International Conference of Education, Research and Innovation (ICERI 2018), L. G. Chova, A. L. Martinez, and I. C. Torres, Eds., pp. 6120-6127pp. 6120-, Valenica, Spain, November 2018.

[31] F. C. Eugenio and A. J. T. Ocampo, "Assessing Classcraft as an effective gamification app based on behaviorism learning theory," in Proceedings of the 2019 8th International Conference on Software and Computer Applications (ICSCA 2019), pp. 325-329, New York, NY, USA, February 2019.

[32] D. H. Torres, N. G. Durant, and C. A. Paredes, "The maze: gamifying the concept of identity," Revista Electrónica Interuniversitaria de Formación del Profesorado, vol. 22, no. 2, pp. 31-42, 2019.

[33] M. Mora Máquez and J. Camacho Torralbo, "Classcraft: inglés y juego de roles en el aula de educación primaria. [Classcraft: English and role play in the primary school classroom]," Apertura, vol. 11, no. 1, pp. 56-73, 2019.

[34] S. Papadakis and M. Kalogiannakis, "Using gamification for supporting an introductory programming course: the case of classcraft in a secondary education classroom," in Interactivity, Game Creation, Design, Learning, and Innovation, A. L. Brooks and E. Brooks, Eds., Springer, Cham, Switzerland, 2018.

[35] M. Grande-de-Prado, R. Baelo, S. García-Martín, and V. Abella-García, "Mapping role-playing games in IberoAmerica: an educational review," Sustainabiliy, vol. 12, pp. 1-12, 2020.

[36] T. Dybå and T. Dingsøyr, "Empirical studies of agile software development: a systematic review," Information and Software Technology, vol. 50, no. 9-10, pp. 833-859, 2008.

[37] D. Hortigüela Alcalá and A. Hernando Garijo, “Teaching games for understanding: a comprehensive approach to promote student's motivation in physical education," Journal of Human Kinetics, vol. 59, no. 1, pp. 17-27, 2017.

[38] S. Arnab, K. Brown, S. Clarke et al., "The development approach of a pedagogically-driven serious game to support Relationship and Sex Education (RSE) within a classroom setting," Computers and Education, vol. 69, no. 1, pp. 15-30, 2013.

[39] C.-H. Chen and H.-C. Yeh, "Effects of integrating a questioning strategy with game-based learning on students' language learning performances in flipped classrooms," Technology, Pedagogy and Education, vol. 28, no. 3, pp. 347-361, 2019.

[40] C.-Y. Hung, J. C.-Y. Sun, and J.-Y. Liu, "Effects of flipped classrooms integrated with MOOCs and game-based learning on the learning motivation and outcomes of students from different backgrounds," Interactive Learning Environments, vol. 27 , no. 8, pp. 1-19, 2018.

[41] F. Cechellaa, G. Abbada, and R. Wagner, "Leveraging learning with gamification: an experimental case study with bank managers," Computers in Human Behavior Reports, vol. 3, no. 2, pp. 1-9, 2021.

[42] L. Cetinkaya, "The effects of problem based mathematics teaching through mobile applications on success," Education in Science, vol. 44, no. 197, pp. 65-84, 2019.

[43] I. Cichy, M. Kaczmarczyk, S. Wawrzyniak et al., "Participating in physical classes using Eduball stimulates acquisition of mathematical knowledge and skills by primary school students," Frontiers in Psychology, vol. 11, pp. 2194-2209, 2020.

[44] C.-M. Hung, I. Huang, and G.-J. Hwang, "Effects of digital game-based learning on students' self- efficacy, motivation, anxiety, and achievements in learning mathematics," Journal of Computers in Education, vol. 1, no. 2-3, pp. 151-166, 2014.

[45] K. Duggal, L. R. Gupta, and P. Singh, "Gamification and machine learning inspired approach for classroom engagement and learning," Mathematical Problems in Engineering, vol. 2021, pp. 1-18, 2021.

[46] A. Ferriz-Valero, O. Østerlie, S. García Martínez, and M. García-Jaén, "Gamification in physical education: evaluation of impact on motivation and academic performance within higher education," International Journal of Environmental Research and Public Health, vol. 17, no. 12, p. 4465, 2020.

[47] H. Haruna, X. Hu, S. K. W. Chu, R. R. Mellecker, G. Gabriel, and P. S. Ndekao, "Improving sexual health education programs for adolescent students through game-based learning and gamification," International Journal of Environmental Research and Public Health, vol. 15, no. 9, pp. 1-26, 2017.

[48] G. W. Hodges, J. S. Oliver, Y. Jang, A. Cohen, D. Ducrest, and T. Robertson, "Pedagogy, partnership, and collaboration: a longitudinal, empirical study of serious educational gameplay in secondary biology classrooms," Journal of Science Education and Technology, vol. 30, no. 1, pp. 331-346, 2021.

[49] H.-T. Hung, "Gamifying the flipped classroom using gamebased learning materials," ELT Journal, vol. 72, no. 3, pp. 296-308, 2018.

[50] G.-J. Hwang, T.-C. Hsu, C.-L. Lai, and C.-J. Hsueh, "Interaction of problem-based gaming and learning anxiety in language students' English listening performance and progressive behavioral patterns," Computers and Education, vol. 106, pp. 26-42, 2017.

[51] G.-J. Hwang, C.-M. Hung, and N.-S. Chen, "Improving learning achievements, motivations and problem-solving skills through a peer assessment-based game development approach," Educational Technology Research and Development, vol. 62, no. 2, pp. 129-145, 2013.

[52] S. Lee, M. Shih, J. Liang, and Y. Tseng, "Investigating learners' engagement and science learning outcomes in different designs of participatory simulated games," British Journal of Educational Technology, vol. 52, no. 10, pp. 1197-1214, 2021.

[53] H.-C. K. Lin, Y.-H. Lin, T.-H. Wang, L.-K. Su, and Y.-M. Huang, "Effects of incorporating augmented reality into a board game for high school students' learning motivation and acceptance in health education," Sustainability, vol. 13, no. 6, pp. 3333-3347, 2021.

[54] N. Magen-Nagar, H. Shachar, and O. Argaman, "Changing the learning environment: teachers and students' collaboration in creating digital games," Journal of Information Technology Education: Innovations in Practice, vol. 18, pp. 61-85, 2019.

[55] K.-L. Ou, Y.-H. Liu, and W. Tarng, "Development of a virtual ecological environment for learning the Taipei tree frog," Sustainability, vol. 13, no. 11, pp. 5911-5931, 2021. 
[56] H. H. Ozer, S. Kanbul, and F. Ozdamli, "Effects of the gamification supported flipped classroom model on the attitudes and opinions regarding game-coding education," International Journal of Emerging Technologies in Learning, vol. 13, no. 1, pp. 109-123, 2018.

[57] Y.-H. Pan, C.-H. Huang, I.-S. Lee, and W.-T. Hsu, "Comparison of learning effects of merging TPSR respectively with sport education and traditional teaching model in high school physical education classes," Sustainability, vol. 11, no. 7, pp. 2057-2032, 2019.

[58] S. Pozo Sánchez, J. López Belmonte, A. Fuentes Cabrera, and J. A. López Núñez, "Gamification as a methodological complement to flipped learning-an incident factor in learning improvement," Multimodal Technologies and Interaction, vol. 4, no. 2, pp. 12-25, 2020.

[59] C. D. Scales, T. Moin, A. Fink et al., "A randomized, controlled trial of team-based competition to increase learner participation in quality-improvement education," International Journal for Quality in Health Care, vol. 28, no. 2, pp. 227-232, 2016.

[60] C.-H. Su, "The effects of students' learning anxiety and motivation on the learning achievement in the activity theory based gamified learning environment," Eurasia Journal of Mathematics, Science and Technology Education, vol. 13, no. 5, pp. 1229-1258, 2017.

[61] E. Vazquez-Cano, S. Mengual-Andrés, and E. López-Meneses, "Chatbot to improve learning punctuation in Spanish and to enhance open and flexible learning environments," International Journal of Educational Technology in Higher Education, vol. 18, pp. 33-53, 2021.

[62] M. Borenstein, L. V. Hedges, J. P. Higgins, and H. R. Rothstein, Introduction to Meta-Analysis, Wiley, Chichester, UK, 2009.

[63] M. Csikszentmihalyi, Beyond Boredom and Anxiety, JoseyBass, San Francisco, CA, USA, 1975.

[64] J. Radoff, Game on: Energize Your Business with Social Media Games, Wiley Publishing, Indianapolis, IN, USA, 2011.

[65] R. M. Ryan and E. L. Deci, "Intrinsic and extrinsic motivations: classic definitions and new directions," Contemporary Educational Psychology, vol. 25, no. 1, pp. 54-67, 2000.

[66] E. A. Linnenbrink, "The dilemma of performance-approach goals: the use of multiple goal contexts to promote students' motivation and learning," Journal of Educational Psychology, vol. 97, no. 2, pp. 197-213, 2005.

[67] M. R. Lepper, J. H. Corpus, and S. S. Lyengar, "Intrinsic and extrinsic motivational orientations in the classroom: age differences and academic correlates," Journal of Educational Psychology, vol. 28, no. 1, pp. 129-137, 2005.

[68] D. M. Scanlon, K. L. Anderson, and J. M. Sweeney, Early Intervention for Reading difficulties: The Interactive Strategies Approach, The Guilford Press, New York, NY, USA, 2nd edition, 2016.

[69] M. Sailer, J. Hense, H. Mandl, and M. Klevers, "Fostering development of work competencies and motivation via gamification," in Competence-based Vocational and Professional Education: Bridging the Worlds of Work and Education, M. Mulder, Ed., Springer, Cham, Switzerland, pp. 795-818, 2017.

[70] G. C. Challco, F. R. H. Andrade, S. S. Borges, I. I. Bittencourt, and S. Isotani, "Toward a unified modeling of Learner's growth process and flow theory," Educational Technology and Society, vol. 19, no. 2, pp. 215-227, 2016.

[71] J. R. Anderson, “Acquisition of cognitive skill," Psychological Review, vol. 89, no. 4, pp. 369-406, 1982.
[72] D. E. Rumelhart and D. A. Norman, Accretion, Tuning and Restructuring: Three Modes of Learning (Report No. 7602), University of California, San Diego, CA, USA, 1976.

[73] S. Isotani and R. Mizoguchi, Edited by R. Mizoguchi, Ed., Edited by P. Dillenbourg, Ed., "An integrated framework for fine-grained analysis and design of group learning activities," in Frontiers in Artificial Intelligence and Applications, Z. Zhu, Ed., pp. 193-200, IOS Press, Amsterdam, The Netherlands, 2006.

[74] A. Inaba, M. Ikeda, and R. Mizoguchi, Edited by U. Hoppe, Ed., Edited by F. Verdejo, Ed., "What learning patterns are effective for a learner's growth," in Proceedings of the International Conference on Artificial Intelligence in Education, J. Kay, Ed., pp. 219-226, IOS Press, Amsterdam, The Netherlands, 2003.

[75] A. Calvo, D. C. Rotaru, M. Freire, and B. Fernandez-Manjon, "Tools and approaches for simplifying serious games development in educational settings," in Proceedings of the 2016 IEEE Global Engineering Education Conference (EDUCON), pp. 1188-1197, IEEE, Abu Dhabi, United Arab Emirates, April 2016.

[76] S. B. Climent and A. A. Martinez, "Game over: cards, role playing games and food," Ford de Profesores de E-Le, vol. 14, pp. 3-26, 2018.

[77] D. Crawley, Classcraft Makes the Classroom a Giant RolePlaying Game-with Freemium Pricing, https://venturebeat. com/2014/05/31/classcraft-role-playing- classroom, 2014.

[78] S. Kim, "Analysis of engineering students' needs for gamification," Journal on Knowledge and Data Engineering, vol. 1, no. 1, pp. 1-7, 2013.

[79] W. Podilchak, "Distinctions of fun, enjoyment and leisure," Leisure Studies, vol. 10, no. 2, pp. 133-148, 1991.

[80] W. B. Strean and N. L Holt, "Coaches', athletes', and parents' perceptions of fun in youth sports: assumptions about learning and implications for practice," Avante, vol. 6, no. 3, pp. 83-98, 2000.

[81] E. L. Deci, R. Koestner, R. M. Ryan, and J. Cameron, "Extrinsic rewards and intrinsic motivation in education: reconsidered once again," Review of Educational Research, vol. 71, no. 1, pp. 1-27, 2001.

[82] A. Gaces, S. Goertler, and S. Spasova, "Planned online education versus crisis-prompted online language teaching: lessons for the future," Foreign Language Annals, vol. 53, pp. 380-392, 2020.

[83] R. Layard and J. Dunn, A Good Childhood: Searching for Values in a Competitive Age, Penguin, Harmondsworth, England, UK, 2009.

[84] K. Ecclestone, Edited by M. Priestley, Ed., "Confident individuals: the implications of an "emotional subject" for curriculum priorities and practices," in Reinventing the Curriculum: New Trends in Curriculum Policy and Practice, G. Biesta, Ed., Bloomsbury, London, UK, pp. 75-98, 2013.

[85] G. Biesta, "Responsible citizens: citizenship education between social inclusion and democratic politics," in Reinventing the Curriculum: New Trends in Curriculum Policy and Practice, M. Priestley and G. Biesta, Eds., Bloomsbury, London, UK, 2013.

[86] J. Dewey, Experience and Education, Macmillan, New York, NY, USA, 1938.

[87] B. Bradley, Well-being, Polity Press, Cambridge, MA, USA, 2015.

[88] J. Arthur and D. Carr, "Character in learning for life: a virtueethical rationale for recent research on moral and values education," Journal of Beliefs \& Values, vol. 34, no. 1, pp. 26-35, 2013. 